\title{
Imaging of soft tissue sarcomas
}

\author{
Dakshesh B. Patel, George R. Matcuk Jr \\ Department of Radiology, Keck School of Medicine and University of Southern California, Los Angeles, CA 90033, USA \\ Contributions: (I) Conception and design: All authors; (II) Administrative support: None; (III) Provision of study materials or patients: None; (IV) \\ Collection and assembly of data: None; (V) Data analysis and interpretation: None; (VI) Manuscript writing: All authors; (VII) Final approval of \\ manuscript: All authors. \\ Correspondence to: Dakshesh B. Patel, MD. Associate Professor of Clinical Radiology, Keck School of Medicine and University of Southern California, \\ 1500 San Pablo Street, $2^{\text {nd }}$ Floor Radiology, Los Angeles, CA 90033, USA. Email: dakshesp@usc.edu.
}

\begin{abstract}
Soft tissue sarcomas are rare and a heterogeneous group of neoplasms. Over the years imaging has played a crucial role in the initial staging, monitoring response to chemotherapy, and surveillance for recurrence. In the era of rapidly evolving individualized treatment due to evolving chemotherapies, increasing demand has been placed on the role of imaging in the management of this heterogeneous group. The rapidly evolving technologies in imaging are trying to keep up with the challenge, with development of newer strategies and hybrid imaging. However, many of these newer technologies are either not available or too costly, even in advanced countries, and hence their exact role remains uncertain. Due to this, and the vast diversity of sarcomas, the imaging appearance and management strategies vary and there is no universally accepted algorithm for the role of individual imaging technologies. The basic imaging techniques; however, remain the same, with these newer techniques and strategies vying for their roles in management. We review current imaging techniques and their role in the management of soft tissue sarcomas.
\end{abstract}

Keywords: Imaging; sarcoma; soft tissue sarcoma; computed tomography; magnetic resonance imaging; positron emission tomography

Submitted Jun 14, 2018. Accepted for publication Jul 20, 2018.

doi: $10.21037 /$ cco.2018.07.06

View this article at: http://dx.doi.org/10.21037/cco.2018.07.06

\section{Introduction}

Soft tissue sarcomas are rare, accounting for approximately $1 \%$ of solid cancers in adults, and represent a heterogeneous group of disorders arising from mesenchymal tissue $(1,2)$. Imaging plays a crucial role in the initial staging, monitoring response to therapy, and surveillance for recurrence. Due to the large variety, distribution, and age range, the detailed imaging of each sarcoma is not possible to review and we will limit our discussion mainly to the extremity soft tissue sarcomas. We will highlight the common imaging modalities and their role in routine sarcoma imaging, and briefly review some of the newer imaging techniques that have potential further role in sarcoma imaging.

\section{Imaging techniques}

\section{Plain radiographs}

The evaluation of all suspected soft tissue sarcomas should begin with plain radiographs, with at least two views orthogonal to each other. It is low cost, universally available, and involves minimal radiation but is limited by its contrast resolution (3). Although its usefulness in the evaluation of soft tissue sarcoma is limited, it can provide important diagnostic information (4). It can sometimes detect the presence of a fat-containing lesion (Figure 1) (5), but more often it is used to detect the presence of and pattern of mineralization that helps establish a diagnosis or narrow the differential. Typical examples of this utility 


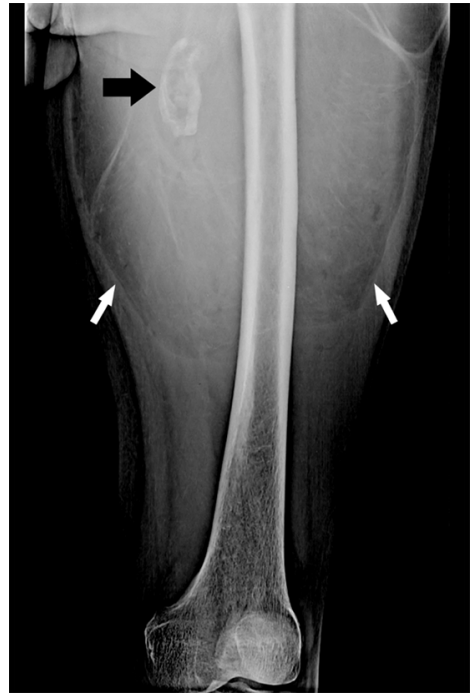

Figure 1 An 88-year-old man with left thigh mass. Plain radiograph shows a large soft tissue mass with fat density (white arrows) with an area of mineralization (black arrow). Although on ${ }^{18} \mathrm{~F}-\mathrm{FDG}$ PET-CT (not shown) the region of mineralization had increased metabolism (SUVmax 4.3), at histopathology this was shown to be an area of metaplastic bone in a well differentiated liposarcoma.

is to distinguish myositis ossificans with its peripheral calcification with central lucent zone reflecting zonal pattern of mineralization, and tumoral calcinosis with its dependent layering of calcium, from other soft tissue masses $(6,7)$. Several soft tissue sarcomas may have mineralization and typical examples include extraskeletal mesenchymal chondrosarcoma, extraskeletal osteosarcoma, liposarcoma, and synovial sarcoma. Chondrosarcomas tend to have chondroid matrix resembling rings and arcs, osteosarcomas dense cloud like mineralization, liposarcomas large and coarse, while the synovial sarcomas can have spicules, stippled sand-like, and/or coarse calcifications (2,8-11). Plain radiographs in many cases distinguishes calcification from ossification, the former being denser while the later having cloud like appearance with or without trabecular pattern (11). Again, this helps narrow the differential indicating the probable type of tissue (e.g., cartilage versus osteoid). The pattern of mineralization also helps exclude a benign lesion as a cause of mass. Phleboliths may be identified which can help steer the diagnosis towards vascular malformation, while typical appearance of amorphous mineralization and bone erosions in typical locations suggests gout (9). Plain radiographs can help identify bone lesions such as osteochondroma which can present as palpable mass, and sometimes help identify the uncommon invasion of bone by soft tissue sarcoma. Most invasion of bone by soft tissue sarcoma is irregular with a wide zone of transition but a smooth pressure erosion only signifies a slow growing tumor and does not exclude a sarcoma (Figure 2) (12).

\section{Computed tomography (CT)}

The current utility of CT in evaluation of soft tissue sarcoma is limited, due to concern for radiation, and less contrast resolution compared to magnetic resonance imaging (MRI) (13). However, in the extremities, radiation is less of a concern compared to the trunk. Based on their ability to attenuate $\mathrm{X}$-rays, the tissues can be broadly divided into fat, fluid, soft tissue, or calcification/ossification density. CT easily identifies fat in fat-containing lesions such as a simple lipoma. However, unless the lesion is composed entirely of homogeneous fat density with or without a few thin delicate septa that show no or mild enhancement, CT cannot reliably distinguish a lipoma/ lipoma variant from well differentiated liposarcoma. The latter commonly will contain nodular or globular nonfatty tissue and/or thick septations which often show enhancement (14). It is better than plain radiographs and other modalities in detection of soft tissue mineralization and differentiating calcification from ossification (12). One particular utility of this is to determine the pattern of mineralization which distinguishes myositis ossificans (zonal phenomena with dense peripheral rim of calcification) from a soft tissue sarcoma which lacks that pattern (Figure 3) (6). $\mathrm{CT}$ is better than plain radiographs in evaluation of cortical invasion but its accuracy in evaluating intramedullary invasion is less than that of MRI (15). The majority of sarcomas have CT attenuation slightly less or similar to that of muscles. Contrast material may be used to detect lesions when they are isodense on a non-contrast study, distinguish a cystic from solid lesion, and evaluate internal vascularity and vascular invasion (12). CT with contrast is the modality of choice for staging if MRI is contraindicated (16). CT angiography can provide an even more sensitive evaluation of vascular invasion (17). It is common modality to guide biopsy. Other advantages include three dimensional (3D) postprocessing techniques that can visually display the anatomy for surgeons. CT may overestimate the extent of soft tissue sarcoma, as it cannot distinguish the surrounding reactive inflammation and edema from the tumor itself (13). One drawback of CT with contrast is the potential for allergic reaction. There was also concern regarding the 

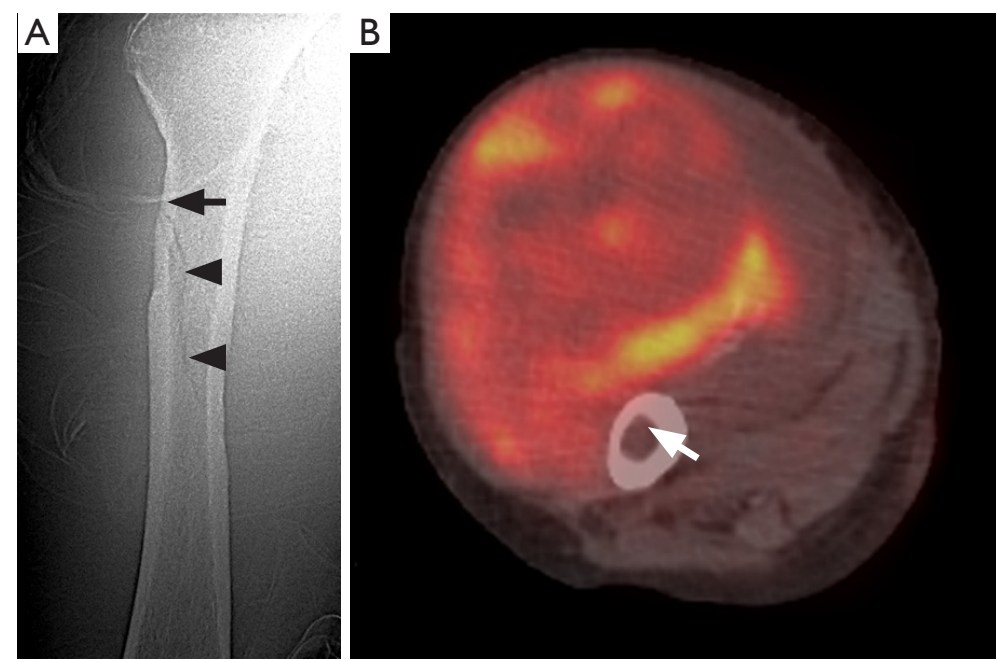

Figure 2 A 72-year-old female with right thigh mass. Plain radiograph (A) shows smooth pressure erosion and thinning of the lateral cortex (black arrow), with nondisplaced pathologic fracture (arrowheads). Fused ${ }^{18}$ F-FDG PET-CT image (B) shows a hypermetabolic mass (SUV max 25.1) with erosion and thinning of the cortex (white arrow). Previous biopsy at outside institute showed a high grade poorly differentiated spindle cell and epithelioid neoplasm.
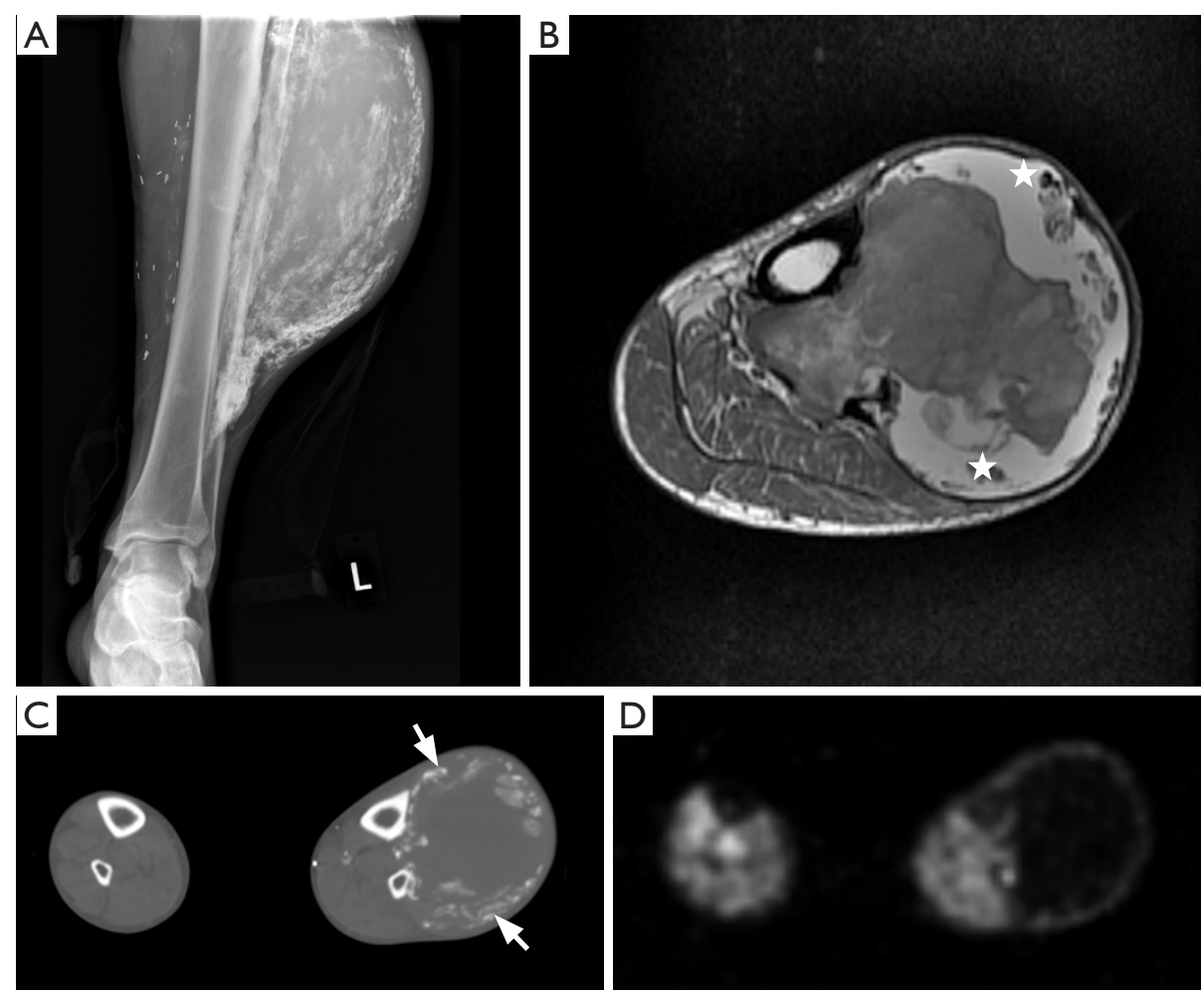

Figure 3 A 50-year-old man with left leg mass. Plain radiograph (A) of the leg shows a mass with peripheral mineralization. Axial T1 weighted (B) image shows heterogeneous mass, with areas of increased T1 signal (stars), which did not show enhancement (pre- and postcontrast T1 weighted with fat saturation (T1FS) images not shown). Due to concern for underlying neoplasm, ${ }^{18} \mathrm{~F}-\mathrm{FDG}$ PET-CT (C and D) was performed which shows predominant peripheral calcification (arrows) seen with chronic hematoma or myositis ossificans. There was no hypermetabolism to suggest an underlying neoplasm. The mass was excised and confirmed to be organizing hematoma at histopathology. 

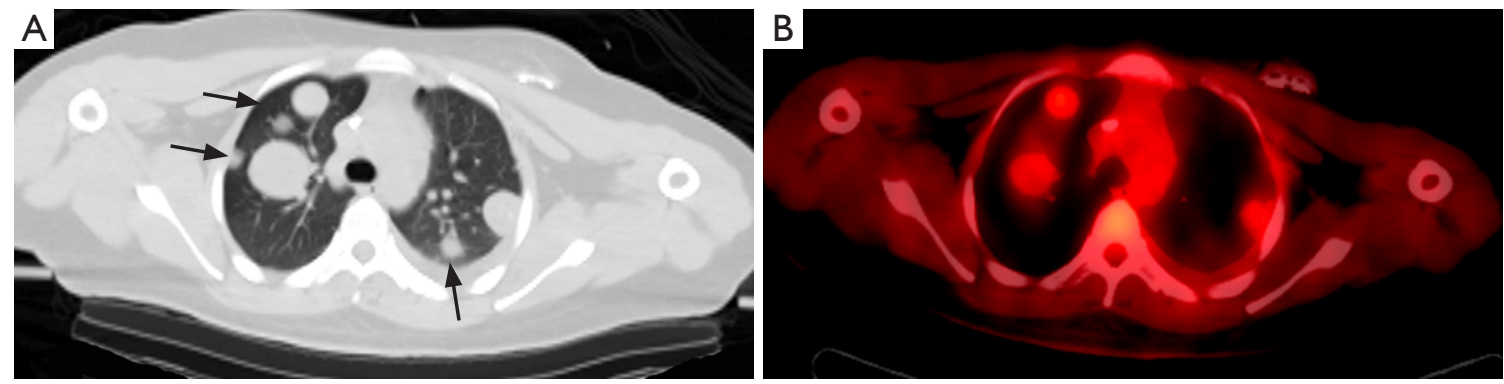

Figure 4 A 16-year-old female with synovial sarcoma of the leg. Axial CT portion of the ${ }^{18}$ F-FDG PET-CT (A) and fused ${ }^{18}$ F-FDG PETCT (B) images show multiple pulmonary metastases (SUVmax 1.7-2). Note multiple smaller metastases (arrows) that are not identified on the fused images.

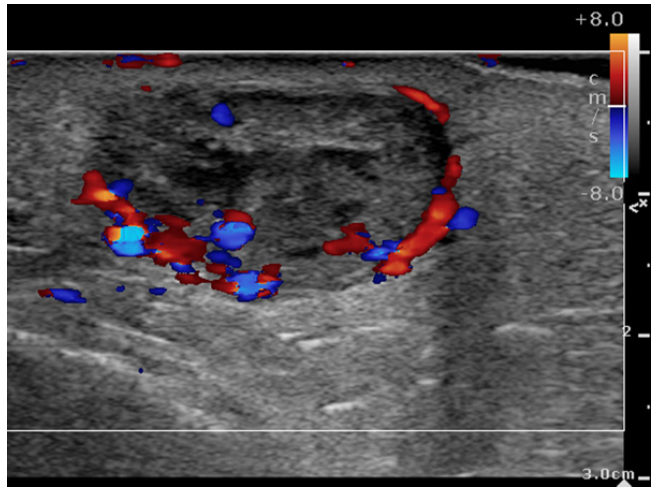

Figure 5 A 62-year-old female with right anterior leg mass. Color Doppler US image shows a solid heterogeneous hypoechoic mass with internal vascularity. The mass does not have typical appearance of a benign lesion. This was surgically excised and was proven to be a synovial sarcoma at pathology.

potential nephrotoxicity of iodinated contrast material, but a recent meta-analysis showed no significant association of contrast enhanced CT with acute kidney injury (18).

When MRI is contraindicated or not available, CT is a useful modality for local surveillance (19). It is comparable to MRI for detection of larger recurrence, greater than $15 \mathrm{~cm}^{3}$. But similar to static post-contrast MRI, it cannot distinguish granulation/fibrosis from residual or recurrent tumor (20). CT is modality of choice for detection of lung metastasis (Figure 4) (21). Compared to plain radiographs, CT can detect lung metastasis earlier, and more accurately identify the number of lesions and segments of involvement for planning of metastasectomy (22).

CT perfusion is an emerging tool for the evaluation of tumor angiogenesis and can help monitor the therapy targeting tumor angiogenesis (23).

\section{Ultrasound (US)}

The main role of ultrasound is as an initial imaging study for evaluation of superficial soft tissue mass. Most superficial extremity soft tissue masses are benign with lipoma being the most common. US confirms the presence of the mass, measures its dimensions and depth, evaluates its internal echotexture and vascularity, and can differentiate a few typical benign tumors and other non-neoplastic lesions such as ganglion cysts from others which need further evaluation (24). Ultrasound is widely available and cheap and does not have the side effects of radiation (25). Color or power Doppler is essential to evaluate the presence of internal vascularity, and differentiate between a cyst and a cystic appearing solid mass (26). Combination of grayscale and color Doppler studies can divide the tumors into cystic, solid, or mixed solid and cystic (complex). Simple cystic masses such as ganglion and synovial cysts are well defined, anechoic with posterior acoustic enhancement, and no internal vascularity on Doppler studies (27). Solid and mixed solid and cystic masses have broad differential and include non-neoplastic lesions such as hematoma and abscess, benign neoplasms such as lipoma and nerve sheath tumor, and sarcoma (28). In general, if the appearance does not conform to the well-recognized US appearance of a benign soft tissue mass such as lipoma or nerve sheath tumor, then it needs to be evaluated further with MRI or biopsied (Figure 5).

Evaluation with US, however, can be limited in a large lesion, deep lesions, or when the lesion is behind bones which preclude penetration of the ultrasound waves. For superficial masses, the sensitivity and specificity of identifying malignancy is $94.1 \%$ and $99.7 \%$ respectively (29). While the sensitivity and specificity of US in distinguishing benign from malignant soft tissue masses is high, the accuracy 

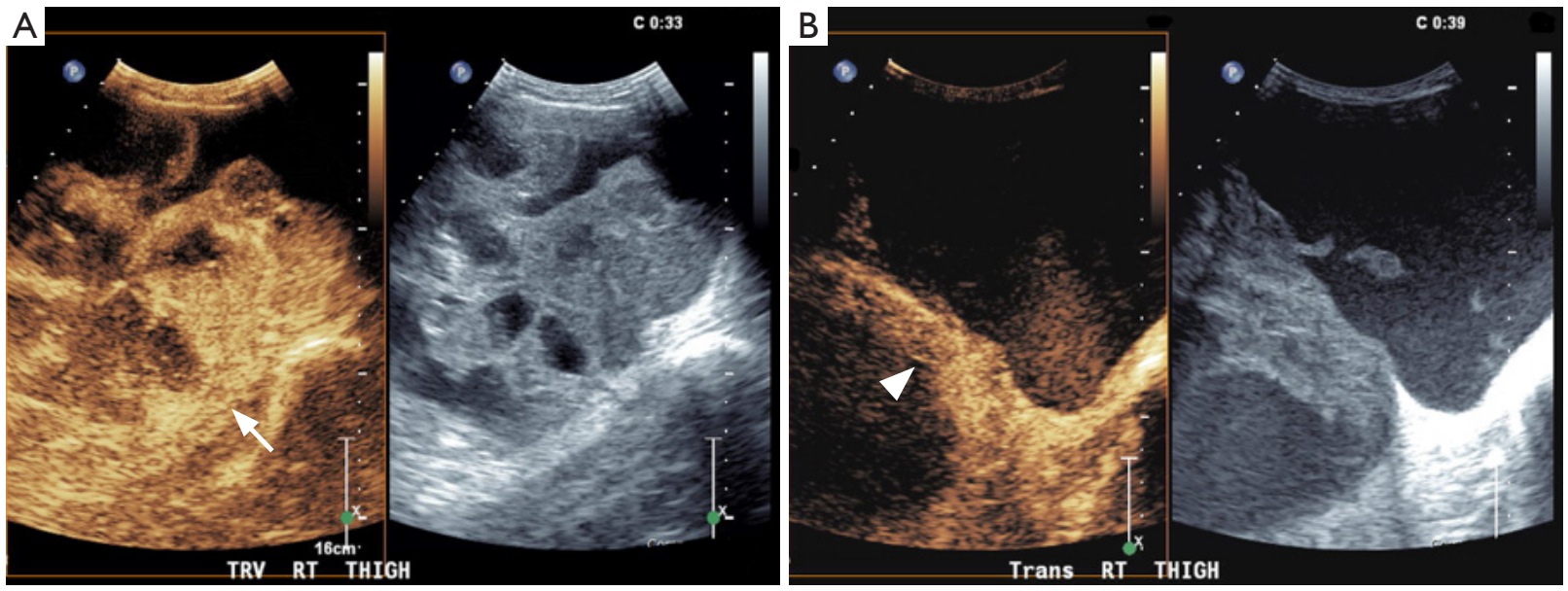

Figure 6 A 55-year-old man with sarcoma of the right leg. Before starting neoadjuvant chemotherapy, CEUS image (A) at peak enhancement shows marked enhancement of the tumor (arrow) with a few small areas of necrosis. Following neoadjuvant chemotherapy (B) there is marked decrease in vascularized viable tissue (arrowhead) with large areas of cystic tumor necrosis.

is dependent on pretest probability. The high accuracy has been attributed to the high pretest probability of the superficial mass as being benign, since benign masses far outnumber malignant masses. US is not only operator dependent but also needs a radiologist experienced in sonography to correctly interpret the findings (28-30).

US is the preferred modality to guide a biopsy (28). Other interventional use of US includes wire localization of a soft tissue mass prior to resection. US is a useful modality for detection of tumor recurrence, particularly when CT scan and MRI are limited due to metallic hardware (19). As with MRI, it is limited in the early postoperative period.

More recently, with wider availability of US contrast material, the role of US in the management of sarcoma has increased. Similar to dynamic contrast enhanced MRI (DCE-MRI), dynamic contrast enhanced US (CEUS) is used to evaluate the vascularity and perfusion of the lesion. Unlike DCE-MRI, the contrast remains in the intravascular compartment and does not diffuse into the interstitium (31,32). Microbubbles of an average size of $0.5-$ 10 micrometer are injected intravenously and its passage through the tumor vessels is monitored and plotted as a time intensity curve. As with DCE-MRI, in CEUS, viable tissue in malignant tumors showed earlier enhancement (time to peak enhancement) compared to benign lesions (32). A classification system based on enhancement pattern (P1-nonenhancement or thin peripheral rim-like enhancement, P2-peripheral enhancement with confluent areas of nonenhancement, $\mathrm{P} 3$-inhomogeneous or patchy enhancement, and $\mathrm{P} 4$-homogeneous enhancement) has been proposed with $\mathrm{P} 2$ or $\mathrm{P} 3$ pattern seen with malignant lesions $(33,34)$. In a preliminary study, CEUS showed potential to monitor the response of neoadjuvant chemotherapy, as seen by decreased enhancement suggesting less viable tissue and increased central areas of nonenhancement suggesting necrosis (Figure 6) (35). Advantages include less cost compared to contrast enhanced CT and contrast enhanced MRI.

US elastography is being investigated for its role in the evaluation of soft tissue masses and sarcoma. It is a method of evaluating tissue stiffness. Ultrasound waves transiently compress and deform tissue and the degree of displacement is measured giving insight to its mechanical property. In general, malignant soft tissue tumors are harder and stiffer and have less elasticity compared to benign soft tissue tumors. One study looking at the strain ratio (ratio of elasticity of the lesion to reference tissue at the same depth) showed that the strain ratios of malignant soft tissue tumors were lower than those of benign tumors (36). Another study looking at the role of strain elastography found it to be useful in differentiating malignant from benign masses with a sensitivity and specificity of $93.8 \%$ and $80.5 \%$ respectively (37). However, another recent study with 105 masses looked at the role of shear wave elastography in evaluating musculoskeletal soft tissue masses and concluded that there was no statistically significant association between shear wave velocity and malignancy, and that there is no additional role for this technique over conventional US (38). 


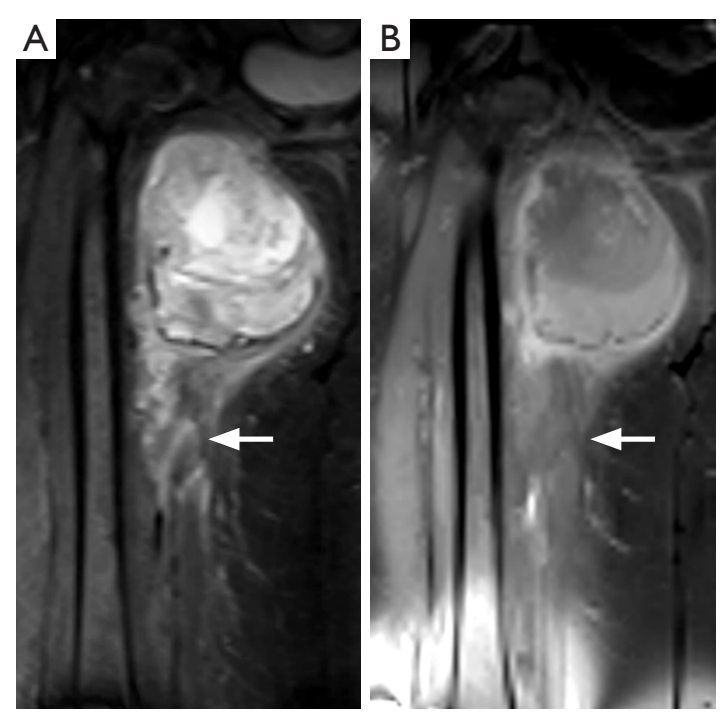

Figure 7 A 64-year-old woman with right thigh mass biopsy proven to be undifferentiated pleomorphic sarcoma. Zoomed coronal STIR (A) and post-contrast T1FS (B) images of the right thigh show peritumoral edema without enhancement (arrows). Static post-contrast T1FS images may not be helpful in distinguishing peritumoral edema from tumor. Peritumoral edema is resected along with the mass as it may contain island of viable tumor cells. (Note the band of increased signal at the inferior aspect of image $B$ which is an artefact due to inhomogeneous fat saturation often seen with frequency selective fat saturation technique).

\section{Magnetic resonance imaging (MRI)}

MRI is imaging modality of choice for evaluation of soft tissue sarcoma, particularly to determine the local extent of the lesion. Lack of ionizing radiation, multiplanar imaging capability, and excellent tissue contrast makes it particularly suitable for evaluation of characteristics and extent of the lesion (4). MRI can not only distinguish between simple cystic lesions and solid masses but can further help narrow the differential and point towards sarcoma as the potential etiology. MRI can evaluate the size and extent of the tumor and identify invasion of the compartments and important structures such as nerves, vessels and joints.

A combination of fat sensitive ( $\mathrm{T} 1$ weighted) and fluid sensitive (proton density weighted/T2 weighted) sequences without and with frequency selective fat saturation are utilized for imaging. Short tau inversion-recovery (STIR) sequence may replace fat saturation fluid sensitive sequences, and has the advantage of more homogenous fat suppression but has lower signal-to-noise ratio and is susceptible to motion artifact. The T1 weighted sequences show fat, melanin and methemoglobin as high signal intensity. The signal from fat suppresses with frequency selective fat saturation, while that from melanin and methemoglobin does not (4). On STIR, the signal from tissues with T1 relaxation times similar to that of fat such as melanin and hemorrhage can also suppress (39). Most sarcomas have high signal on fluid sensitive sequences. Surrounding reactive peritumoral edema is also hyperintense but has normal or very little T1 signal abnormality (Figure 7) (40). Despite this, the two are difficult to distinguish, and static post contrast imaging is also not helpful in this regard (41). $\mathrm{T} 2 *$ gradient echo imaging, although rarely performed, can show hemosiderin as signal loss with blooming (42).

Evaluation of static T1 weighted images after intravenous administration of gadolinium-based contrast material, when the contrast is in equilibrium between the interstitium and plasma, is a standard practice for evaluation of a soft tissue mass. The use of contrast material may be contraindicated either due to allergy or risk of nephrogenic systemic fibrosis. Whether to use fat saturation or not depends on individual preference, but subtraction images, where the precontrast $\mathrm{T} 1$ weighted images are digitally subtracted from post-contrast images, are helpful when evaluating for subtle enhancement. For this, it is imperative to obtain a baseline precontrast $\mathrm{T} 1$ weighted sequence and use the same parameters for post-contrast imaging in the same plane. Contrast administration helps in identification of vessels and their direct invasion by tumor. It gives insight in to tumor vascularity (43). The area with most intense enhancement is more likely to represent the most aggressive and highest grade of the tumor (44).

\section{Dynamic contrast enhanced MRI (DCE-MRI)}

A dynamic contrast enhanced study, utilizing gradient echo sequence, is used for evaluation of enhancement pattern of the tumor over the initial 2-3 minutes following a rapid intravenous bolus injection of gadolinium based contrast material followed by a saline flush. Quantitative timeintensity curves are generated by operator dependent placement of region of interest (ROI) (Figure 8).

DCE-MRI gives information of tissue perfusion, vascularization, capillary permeability and volume of interstitial space that is not available with static imaging (45). It helps in assessment of viable tissue, and identifying the area of most rapid enhancement which is potentially the site of highest grade in the tumor and thus a preferable site 


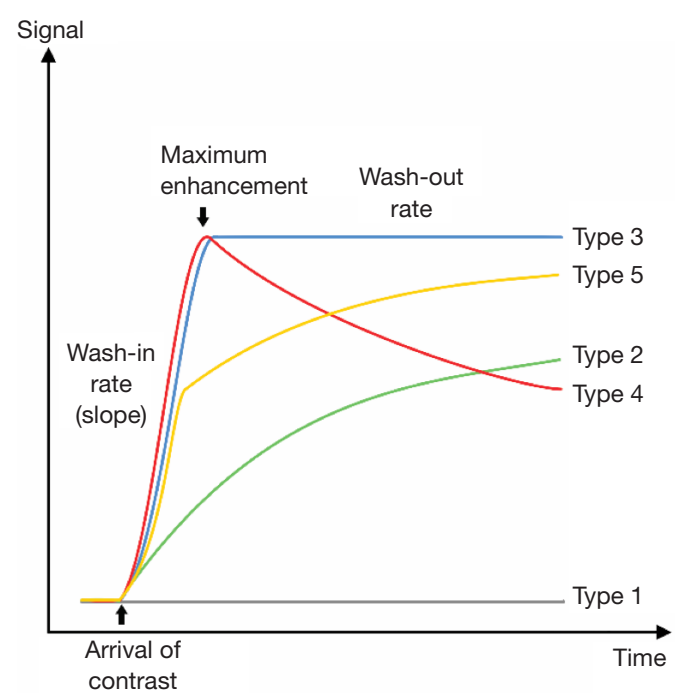

Figure 8 Dynamic contrast enhanced MRI-time-signal intensity curve. Time intensity curve shows the time when the enhancement begins, the enhancement rate during the first pass (slope), maximum enhancement, and the washout rate. A typical malignant lesion will have early, rapid and intense enhancement with washout of contrast (type 4), a typical benign lesion will show slow and gradual enhancement (type 2), while a cyst or hematoma will show no enhancement (type 1). Type 3 enhancement is seen in benign vascular tumors, desmoid tumors and some malignant tumors. Type 5 enhancement is seen in tumors after chemotherapy or radiation therapy, and myxoid tumors.

of biopsy $(44,46)$. It differentiates between the tumor and the peritumoral edema (the latter enhances later) that is not possible with static post-contrast images (44). Although there is significant overlap, it can help differentiate a malignant soft tissue tumor from a benign soft tissue tumor, or at least narrow the differential diagnosis (47). In one study, a combination of maximum relative enhancement in first minute, and in second minute, and steepest slope of enhancement had an overall accuracy of $95.5 \%$ in differentiating malignant from benign soft tissue tumors (48). Malignant tumors show areas of necrosis, and peripheral or inhomogeneous dynamic contrast enhancement that is early, rapid and intense (within 6 seconds after arterial enhancement) followed by a plateau or washout $(47,49,50)$. Highly vascularized/perfused benign lesions such as nerve sheath tumors and desmoid-type fibromatosis may have characteristics similar to malignant tissue $(48,50)$. After starting neoadjuvant chemotherapy, DCE-MRI is useful in monitoring the tumor response, identifying viable tumor tissue (Figure 9) $(44,46)$. A poor response may affect the feasibility of curative surgery, and necessitate a change of chemotherapy. Later, during surveillance after surgery, it can help identification of a residual or recurrent tumor, which commonly shows early, rapid and intense contrast enhancement, and differentiate it from inflammatory change and pseudotumor (Figure 10) $(44,46)$. Radiation-induced pseudotumor (also known as inflammatory pseudotumor or pseudomass) is an ovoid illdefined area of enhancement, without or with little mass effect. Caution should be exercised as early granulation tissue may mimic viable tumor.

\section{Diffusion weighted imaging (DWI)}

It provides a qualitative and quantitative assessment of tissue cellularity and cell membrane integrity. DWI measures Brownian (random) motion of the water molecules in the tissue (51). The three main tissue compartments include the extracellular compartment, intracellular compartment and the intravascular compartment (microcirculation-perfusion). In general, with increased cellularity and membrane integrity, there is decreased size of the extracellular compartment, and higher restriction of motion of the water molecules. On the other hand, necrosis leads to membrane breakdown leading to expansion of the extracellular space, and thus increasing the diffusion (52). A map of apparent diffusion coefficient (ADC) is generated as a quantitative measure of diffusion at each pixel (51).

There is larger motion of the water molecules in the intravascular compartment, compared to the other compartments. Its contribution to the total diffusion depends on the degree of vascularization of the tissue. In highly vascularized tissues, as seen in malignancy, this increases the ADC values. Diffusion images corrected for perfusion eliminates or decreases the contribution of perfusion to the overall diffusion (51-53). The DWI images and the ADC map images are read together with increased signal on DWI and decreased signal on ADC map images indicating restricted diffusion.

Overall, DWI provides the measure of tissue cellularity and membrane integrity rather than whether the lesion is malignant or benign. Highly cellular tissues restrict diffusion more than less cellular tissue and have lower ADC values. This is reflected as higher signal on DWI map images but decreased signal on ADC map images. Malignant lesions, being more cellular and with relatively larger cell size, restrict diffusion more than benign lesions (particularly with myxoid component) and thus 

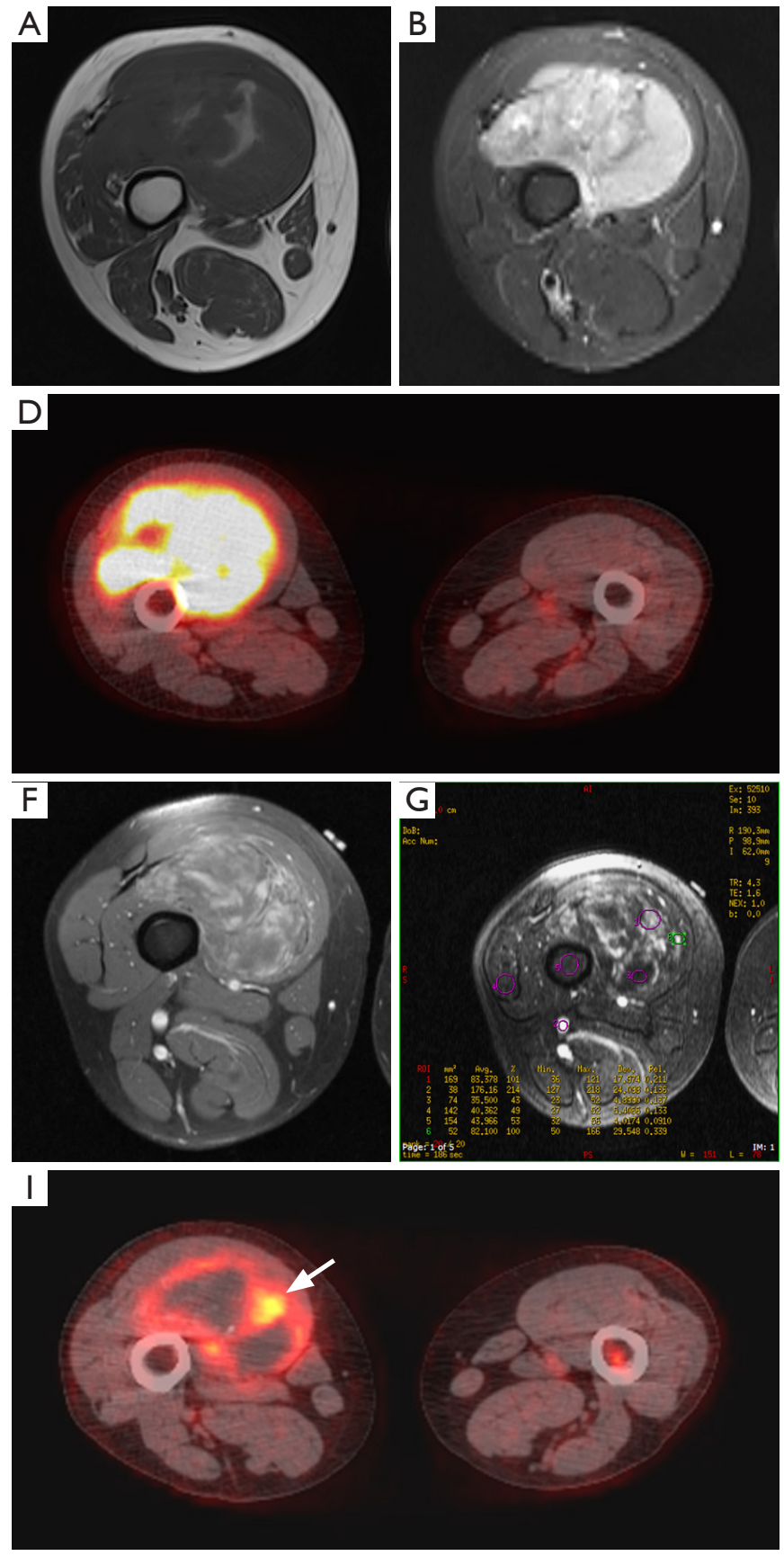
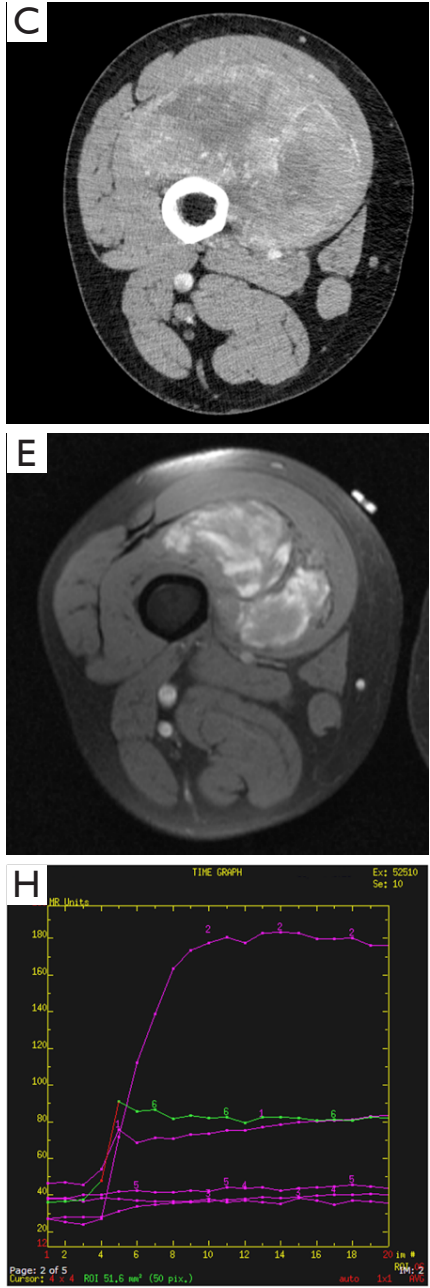

Figure 9 A 31-year-old man with right thigh mass proven to be synovial sarcoma. Axial T1 weighted (A) and STIR (B) MRI images of the initial study performed at an outside institute without administration of intravenous contrast shows mass in the anterior compartment of the right thigh. Frequency selective fat saturation sequence was not obtained which makes it difficult to distinguish fat from hemorrhage. Post contrast axial CT image (C) obtained close to the initial presentation shows heterogeneously enhancing mass and the fused ${ }^{18} \mathrm{~F}$-FDG PET-CT image (D) shows intense hypermetabolic activity (SUVmax 8.2). Neoadjuvant chemotherapy was given. Subsequent axial T1FS (E) and post contrast T1FS (F) MRI images show areas of hemorrhage seen on precontrast image, and heterogeneous areas of enhancement after contrast. DCE-MRI images $(\mathrm{G}$ and $\mathrm{H})$ show few viable areas of tumor with early moderate enhancement with plateau (green line). On fused ${ }^{18}$ F-FDG PET-CT image (I), there is decrease in metabolism (SUVmax 3.1) with central areas of hypo- absent metabolism suggesting favorable response. Note area of more active metabolism (arrow) indicating viable tumor. This corresponds to the region of viable tumor, thus providing complementary information as that with DCE. 

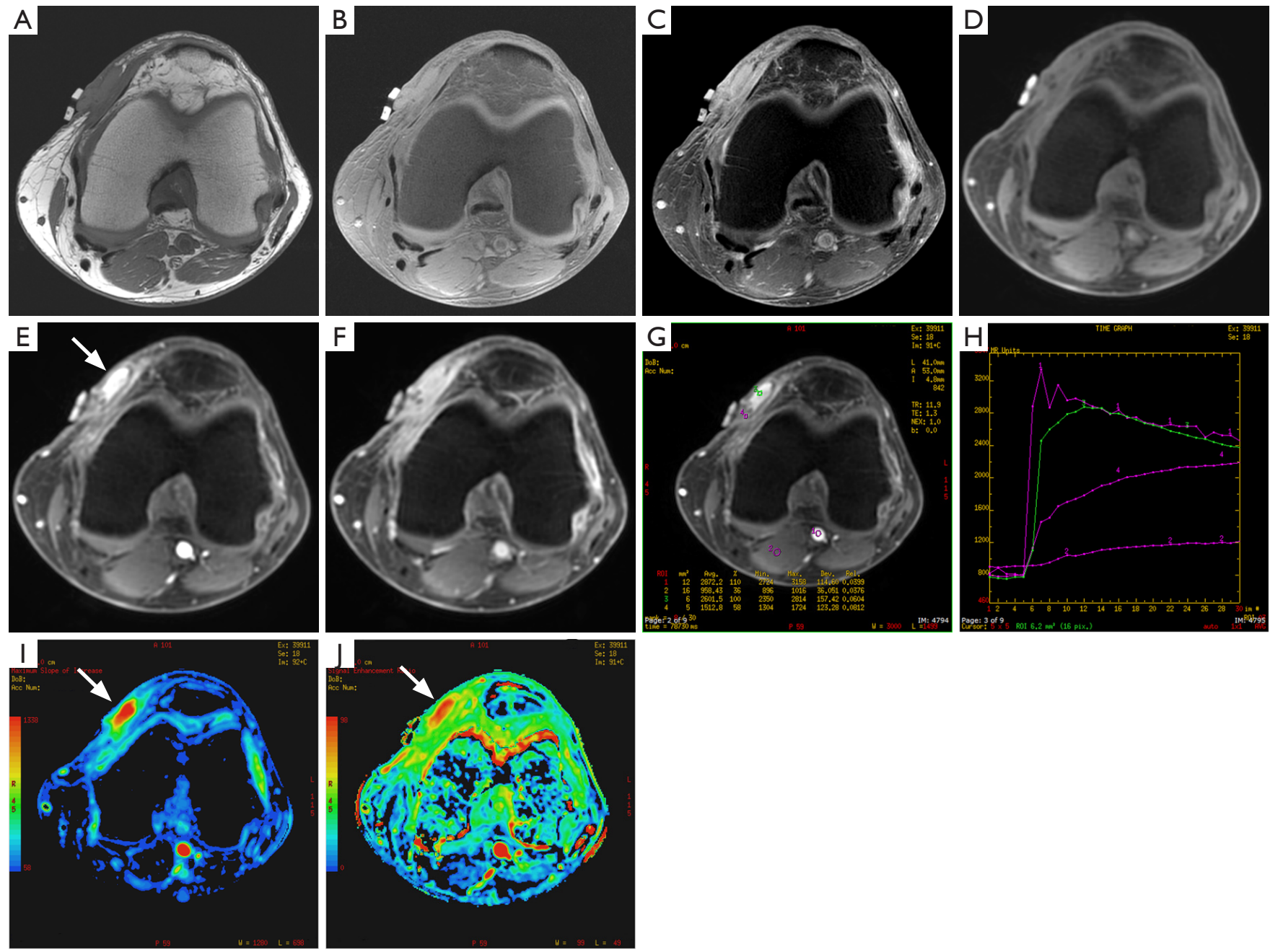

Figure 10 A 64-year-old man with history of marginal resection of an undifferentiated pleomorphic sarcoma at an outside institute. Axial T1 weighted (A), precontrast T1FS (B) and post-contrast T1FS (C) images show isointense region of abnormality on precontrast examination that enhances on post-contrast study. It is not possible to differentiate the residual tumor from surrounding post-surgical granulation and scarring. Three images from a dynamic sequence-before (D), during early enhancement phase (E), and in the delayed phase (F) show early intense enhancement of the residual tumor (arrow) compared to the surrounding granulation and scarring. On the delayed phase the enhancement of the two becomes similar to each other, with decrease in intensity of the residual tumor and increase in intensity of the granulation/scarring. The parametric maps are generated by manually operator dependent placement of regions of interest (G) (1: artery, 2: muscle, 3: tumor, 4: granulation tissue) and can be displayed as time-signal intensity curve (H), or as maximum slope of enhancement (I) and signal enhancement ratio $(\mathrm{J})$ maps. Note early enhancement and wash-out of the tumor (green line in $\mathrm{H}$ ).

can potentially differentiate them from benign lesions (Figure 11) (51,54). However, as with dynamic contrast enhancement, there is considerable overlap between the two (55). DWI can help identify residual or recurrent tumor, and differentiate it from a radiation-induced pseudotumor or postoperative granulation tissue or scarring (56). In response to chemotherapy, there is increase in diffusion related to the tumor necrosis $(51,57)$.

\section{Magnetic resonance spectroscopy (MRS)}

Proton $\left(\mathrm{H}^{1}\right)$ MRS is not as frequently used in sarcoma imaging as that in brain tumors, and is still considered largely a research tool with only a few articles published evaluating its utility in differentiating benign from malignant lesion, 

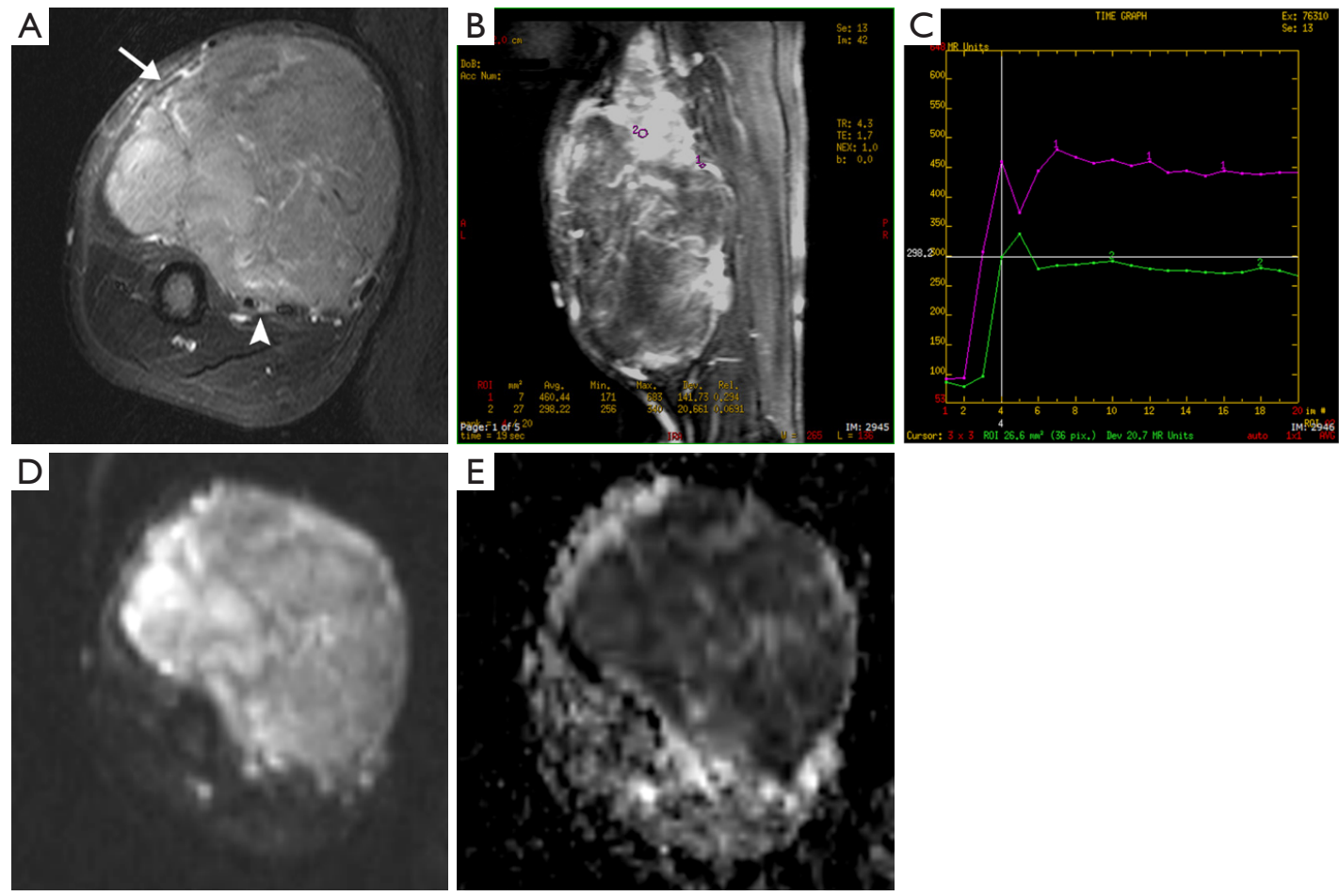

Figure 11 A 65-year-old man with high grade pleomorphic sarcoma of the right arm and extrapulmonary metastasis (not shown) was treated with chemotherapy. Axial post-contrast TIFS MRI image (A) shows enhancing mass (arrow) abutting the brachial neurovascular structures (arrowhead). On sagittal DCE-MRI (B and C), there is early moderately intense type-3 tumor enhancement (green curve). DWI (D) and ADC map (E) images show increased signal on DWI and decreased signal on ADC suggesting restricted diffusion. The relative lack of necrosis and the findings on DCE-MRI, and DWI and ADC map images are compatible with poor chemotherapy response.

monitoring treatment response, and postsurgical follow up $(58,59)$. However, the principles remain the same. There is increase in choline, a membrane phospholipid, in tissues with increased cell membrane turnover such as sarcoma (Figure 12) $(59,60)$. Its concentration can be measured in absolute terms or relative to noise or creatine. Care is taken to avoid including areas of necrotic or hemorrhagic foci, gas, calcification, bone and muscle in the sample.

A discrete elevated choline peak can diagnose malignancy with a sensitivity and specificity of $88 \%$ and $68 \%$ respectively, while a very low concentration $(<0.3 \mathrm{mmol} /$ $\mathrm{kg}$ ) had a negative predictive value of $100 \%$ for excluding malignancy. Elevated choline peak can however also be seen in benign lesions such as peripheral nerve sheath tumor and in abscesses $(58,61)$. A lipid peak is seen in solid component of malignant tumors and in treated tumors (62).

\section{Whole body MRI (WBMRI)}

Recently, with availability of larger field of view, moving table top, and software to stitch together images from different stations, WBMRI has gained interest in screening patient for malignancy in patient with known genetic mutations (such as TP53 germline mutation) that predispose them to developing tumors with increased frequency and at earlier age compared to the general population (63). In sarcomas that have tendency to metastasize to bone, such as myxoid liposarcoma, WBMRI may be useful for evaluation of the skeleton at initial staging or subsequent surveillance (64).

\section{Nuclear scintigraphy}

Tc-99m-methyl diphosphonate bone scan has limited role in the initial evaluation of soft tissue sarcoma. The potential use is to evaluate for bone metastasis. Since bone metastasis from soft tissue sarcoma is rare, unless there is already metastasis to lungs, bone scintigraphy is only used for evaluation of symptomatic patients (65). In a patient 

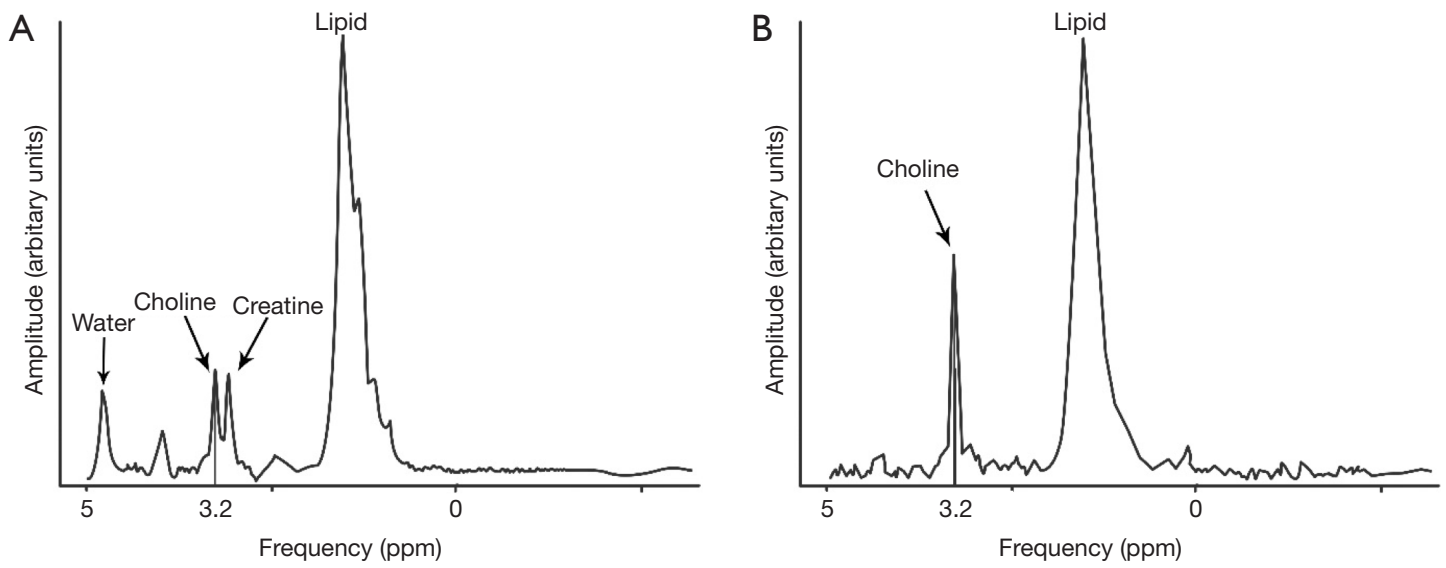

Figure 12 MR spectroscopy (MRS) of normal muscle (A) demonstrates various peaks of metabolites, which are separated by their resonance frequency in parts per million (ppm), with the amplitude dependent on concentration. MRS of a malignant tumor (B) shows elevation of the choline peak relative to background noise.

with known sarcoma with a symptomatic bone metastasis, it can identify additional areas of bone involvement that can be targeted for biopsy, if necessary. In addition, it can draw attention to an asymptomatic metastasis that has potential risk of pathologic fracture.

\section{${ }^{18} \mathrm{~F}$-fluorodeoxyglucose positron emission tomography- computed tomography $\left({ }^{18}\right.$ F-FDG PET-CT $)$}

${ }^{18}$ F 2-fluoro-2-deoxy-D-glucose $\left({ }^{18} \mathrm{~F}\right.$-FDG) positron emission tomography has been evaluated for characterization and grading of soft tissue sarcoma. ${ }^{18} \mathrm{~F}$-FDG, being a glucose analogue, is actively transported in to the tumor cells depending on their rate of metabolism, and standardized uptake value (SUV) acts as the measure of the degree of metabolism. ${ }^{18} \mathrm{~F}$-FDG uptake correlates with the histologic grade of the tumor, with intermediate to high grade tumors having higher uptake than low grade tumors (66). There is strong correlation between SUV and pathological grade, cellularity, cell proliferation as indicated by mitotic activity and MIB-1 labeling index, and p53 overexpression (67). The degree of uptake has also been used to discriminate between benign lesions and soft tissue sarcomas. In a meta-analysis by Ioannidis, using an SUV of 2.0 as a cutoff, and higher SUV indicating malignant lesion, the sensitivity and specificity of ${ }^{18} \mathrm{~F}$-FDG PET are $87 \%$ and $79 \%$ respectively, while using the SUV of 3.0 they are $70 \%$ and $87 \%$ respectively (66). There is however significant overlap between low grade sarcomas and inflammatory and benign highly cellular or metabolically active lesions (Figure 13) (66). Thus, in an individual case the utility of ${ }^{18}$ F-FDG PET may be limited, unless the SUV is significantly high. Pretreatment SUV has been shown to correlate with outcome, with high SUV associated with shorter disease-free interval and overall survival (68). SUV and heterogeneity of uptake were found to be independent predictor of survival, and disease progression and outcome respectively (69). Pretreatment tumor necrosis as determined by ${ }^{18} \mathrm{~F}$-FDG PET-CT has also been shown to correlate with prognosis and mortality in sarcomas (70).

The ${ }^{18} \mathrm{~F}$-FDG PET-CT also helps staging by evaluating the extent of the disease. It can look for additional lesions and distant spread including that to lymph nodes, bones, and lungs (Figure 14). ${ }^{18}$ F-FDG PET-CT can identify increased metabolism in normal size lymph nodes (71). It is necessary to emphasize, that metastasis to lymph nodes is extremely uncommon in sarcomas except for a few (e.g., rhabdomyosarcoma, angiosarcoma, clear cell sarcoma, epithelioid sarcoma, synovial sarcoma) $(72,73)$.

In regard to lung metastases, ${ }^{18} \mathrm{~F}$-FDG PET has lower sensitivity but higher specificity compared to CT alone (Figure 3). This is likely related to limited resolution of ${ }^{18}$ F-FDG PET and lack of good blood supply compared to the original tumor $(74,75)$.

Overall, ${ }^{18} \mathrm{~F}$-FDG PET-CT is a valuable tool in initial staging of the sarcoma, but according to the American College of Radiology appropriateness criteria, the role of ${ }^{18} \mathrm{~F}$-FDG PET-CT in the evaluation of soft tissue sarcoma is not yet fully established and it is not typically used for initial assessment of soft tissue mass. It can be 

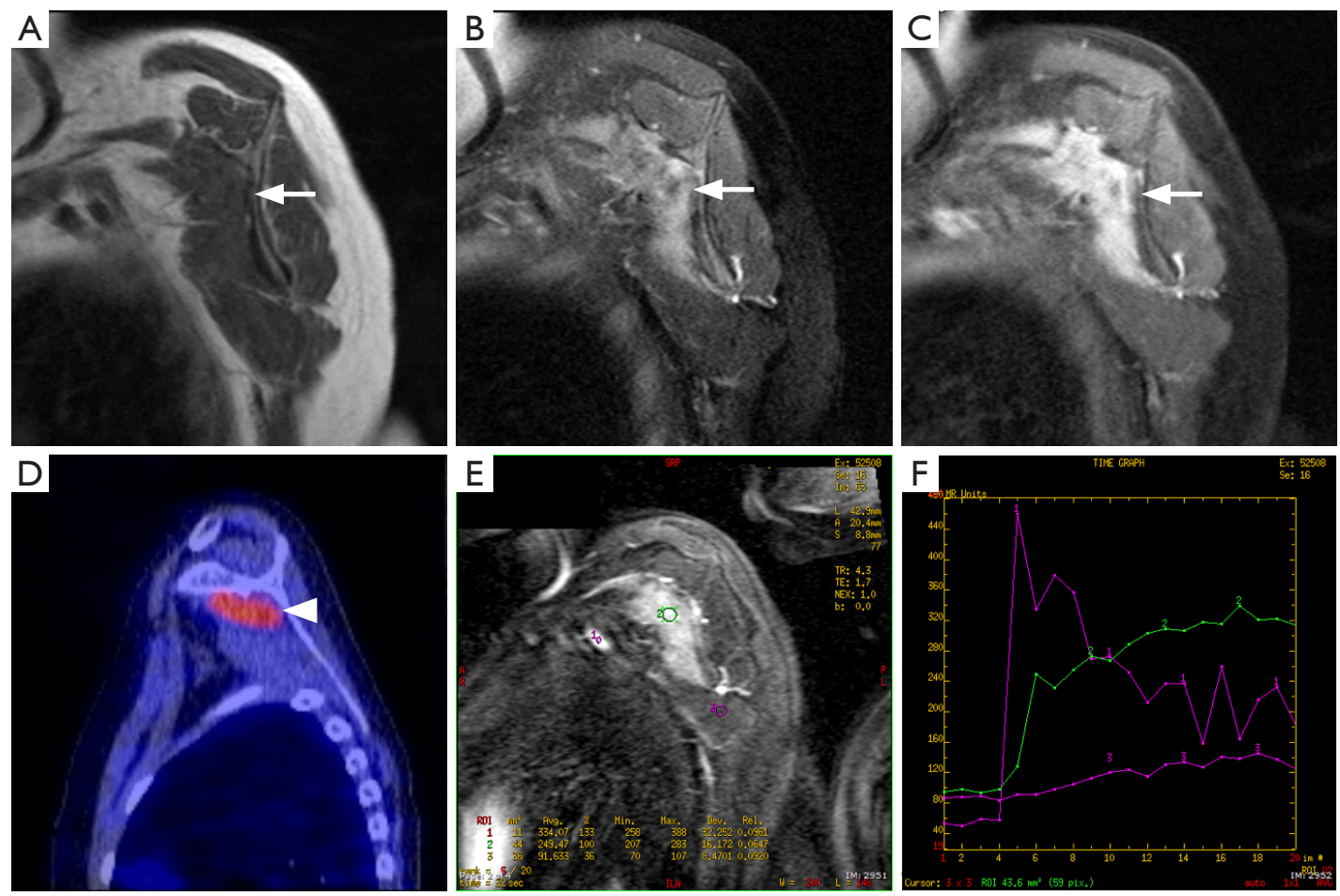

Figure 13 A 13-year-old boy with left shoulder pain. Sagittal T1 weighted (A), T2FS (B) and post contrast T1FS (C) images show isointense T1, heterogeneous slightly hyperintense T2 weighted with fat saturation (T2FS), enhancing mass (arrows) in the subscapularis fossa infiltrating the muscle. Sagittal fused ${ }^{18}$ F-FDG PET-CT image of the left shoulder (D) shows increased metabolism (arrowhead) with SUVmax of 2.7, raising a possibility of malignant lesion. However, time signal intensity-curve on DCE-MRI image (E and F) shows early moderate but progressive enhancement (green line). Open surgical biopsy was performed due to the location of the lesion which at pathology was desmoid-type fibromatosis.
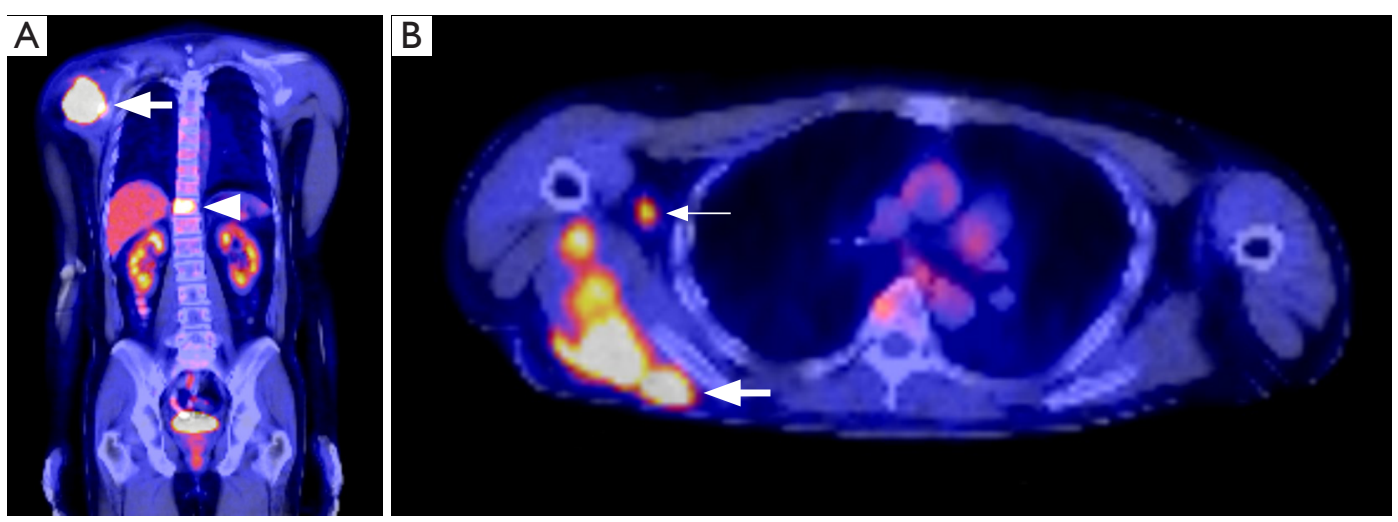

Figure 14 A 50-year-old man with parascapular rhabdomyosarcoma. Coronal (A) and axial (B) fused ${ }^{18}$ F-FDG PET-CT images show a hypermetabolic right shoulder mass (thick arrows, SUVmax 13.9) and spinal metastasis (arrowhead, SUVmax 7) and lymph node metastasis (thin arrow, SUVmax 5.7). ${ }^{18} \mathrm{~F}-\mathrm{FDG}$ PET-CT upgraded the staging in this case. 

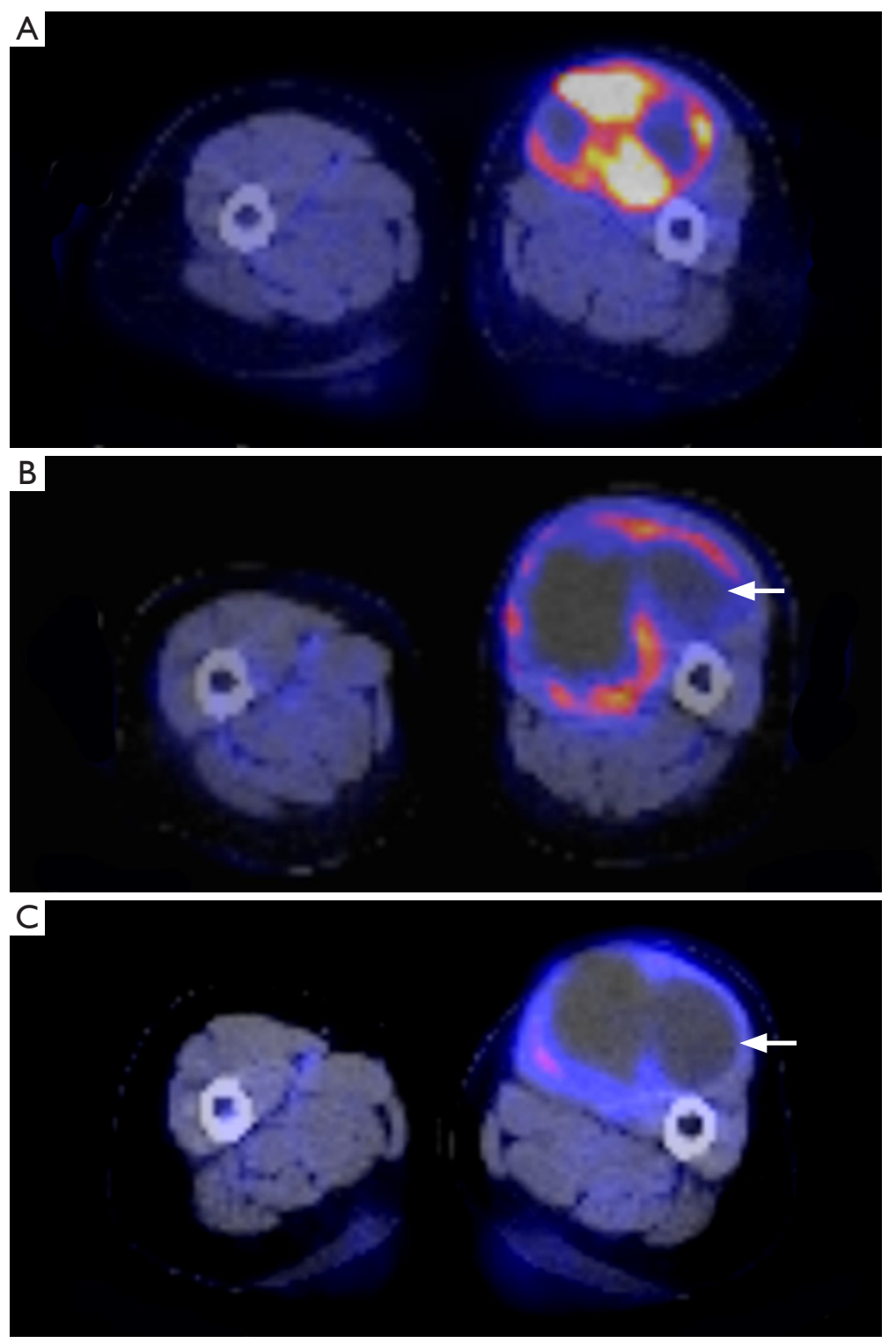

Figure 15 A 61-year-old woman with left thigh mass. Fused ${ }^{18}$ F-FDG PET-CT image (A) at the time of initial presentation shows areas of very high metabolism (SUVmax 14.9). Following neoadjuvant chemotherapy, on ${ }^{18}$ F-FDG PET-CT obtained approximately at 3 months (B) and 5 months (C) after the initial study, there is progressive decrease in metabolism with SUVmax of 10.2 and 3.2, respectively. Note enlargement of the mass. There may be paradoxical increase in size due to hemorrhage and necrosis, as in this case seen as large area of central photopenia (arrows).

used to identify the target area of biopsy, detect metastasis, assess treatment response (Figure 15), and distinguish hemorrhagic tumor and hematoma (Figure 2) (16,76). As with the dynamic contrast enhanced ultrasound and dynamic contrast enhanced MRI, ${ }^{18} \mathrm{~F}$-FDG PET is useful in evaluation of response to chemotherapy $(77,78)$. It is an excellent modality for evaluation of local recurrence and metastasis, particularly the former when MRI and CT are limited by metal artifact. The main drawback of ${ }^{18} \mathrm{~F}$-FDG PET-CT is related to the radiation exposure and availability. Its routine use however needs to be explored further with emphasis on cost benefit analysis and outcome measures, particularly with advances in other modalities with less or no radiation (79). 

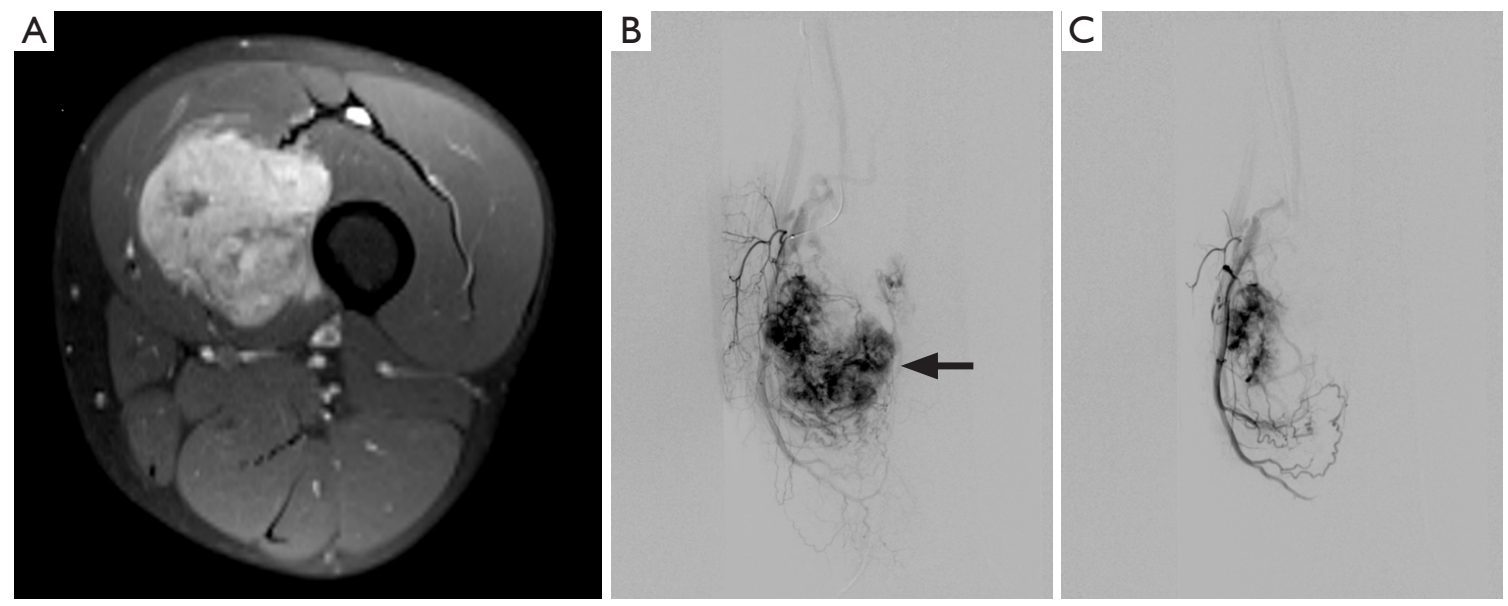

Figure 16 A 32-year-old man with alveolar soft part sarcoma. Post-contrast axial T1FS (A) image shows an intensely enhancing hypermetabolic mass. At open biopsy the mass bled excessively and preoperative embolization was performed. Initial angiographic image (B) shows the vascularity of the mass (arrow) which decreased as seen on post embolization image (C).

${ }^{18}$ F-FDG PET-MRI, a newer imaging technique which promises to combine the best of ${ }^{18} \mathrm{~F}$-FDG PET and MRI, is promising but further studies are needed to establish its role in evaluation and treatment of soft tissue sarcoma $(80,81)$.

\section{Direct arteriography}

Direct arteriography currently has very limited role in evaluation of soft tissue sarcoma, having been replaced by other imaging modalities. It is performed as a part of vascular intervention procedure such as embolization or isolated limb perfusion chemotherapy (Figure 16) (82).

\section{Image guided biopsy}

Adequate tissue representing different components of the sarcoma is a must for complete pathologic evaluation which includes special techniques such as immunohistochemistry, and molecular testing. While necrosis is a feature of malignancy, biopsy sample comprising only or mostly of necrotic tissue is inadequate for complete evaluation. Although the debate is still going on as to whether core needle biopsy or open biopsy should be performed, fine needle aspiration (FNA) biopsy has limited role and its use is mostly limited to confirm local recurrence or metastasis that usually mimics the histology of original tumor. It yields only small amount of tissue, does not allow for the evaluation of tissue architecture, and specimen may not be adequate for additional studies such as molecular testing

\section{$(21,83)$.}

Image guided core needle biopsy can be performed with less complications, morbidity and cost compared to open biopsy, giving good tissue sample. There is also less risk of contamination with coaxial technique and although the potential for inadequate sampling remains, it can be repeated with the accuracy after repeat biopsy as high as 94\% (84). With large gauge biopsy needles, inadequate sampling is uncommon, particularly if a cytopathology technologist is immediately available to evaluate the sample. Open biopsy is costly with complication rates up to $16 \%$, but is more accurate in determining malignancy and exact diagnosis (grade and subtype) compared to core needle biopsy with accuracy close to $100 \%(85,86)$. The choice of needle type and gauge is dependent on the radiologist preference and location of the lesion in relation to vital structures. Both ultrasound and CT scan can be used for biopsy depending on the radiologists' preference, site of the mass, and location of the potential highest-grade component.

The biopsy should be performed after imaging since hemorrhage and edema/inflammation associated with biopsy can alter the imaging appearance of the tumor (87). Prior imaging can identify the potential site of highest tumor grade which needs to be targeted. The biopsy of a suspected soft tissue sarcoma should only be performed after consultation with an orthopedic surgeon, to determine the best approach to biopsy. While the shortest path to the lesion is preferred, crossing an uninvolved compartment as 
well as important vessels, nerves, joint and vital structures should be avoided (87). The biopsy tract is resected en bloc along with the mass (83).

\section{Role of imaging}

Imaging establishes the presence and location of the soft tissue mass, identifies a definitely benign lesion and separates them from indeterminate or possibly malignant lesions, narrows the differential based on imaging characteristics of the tumor, and identifies the local extent (local staging) of the lesion and its relation to the compartment anatomy, vessels, nerves, bone and joint. Its role in biopsy has already been discussed. Once a diagnosis of soft tissue sarcoma is established by biopsy, imaging is used to identify distant metastasis and stage the tumor. Imaging helps monitor response to neoadjuvant chemotherapy and once definitive surgery is performed, is used for monitoring for local recurrence and distant metastasis.

Apart from the imaging appearance and local invasion, specialized imaging techniques such as DCE-MRI and DWI and in selected cases ${ }^{18} \mathrm{~F}-\mathrm{FDG}$ PET-CT helps identify the potentially malignant lesions. As discussed, while no individual or a combination of features can categorize the lesion as benign or malignant, a combination of features can suggest the possibility of a lesion being malignant. Overall, in one study looking at the value of MRI for differentiating malignant from benign soft tissue masses, T1 signal heterogeneity, absence of low signal on $\mathrm{T} 2$, and mean diameter $>33 \mathrm{~mm}$ showed highest sensitivity, while necrosis, bone or neurovascular involvement or metastases, and mean diameter $>66 \mathrm{~mm}$ showed highest specificity (88). Liposarcomas, leiomyosarcomas, undifferentiated pleomorphic sarcomas, synovial sarcomas, myxofibrosarcomas and fibrosarcomas are the most common sarcomas and make up about two thirds of the soft tissue sarcomas. There is considerable overlap of imaging characteristics of benign and malignant lesions and they cannot be reliably differentiated (87). In general, benign soft tissue tumors far outnumber malignant soft tissue tumors (89).

\section{Imaging evaluation and characterization of mass}

While characterizing tissue type is and will remain the domain of pathology, which is the gold standard, a small list of differential diagnosis needs to be provided depending on the imaging features. Based on signal characteristics, lesions can be classified into four broad categories. The first group has signal characteristics consistent with fat (high signal on T1 weighted sequence), where the tissue follows the signal of subcutaneous fat or yellow marrow on all pulse sequences, and the signal suppresses equally to fat with frequency selective fat saturation and STIR imaging. In sarcoma imaging, this is consistent with liposarcoma when benign fat containing lesions such as lipoma, lipoma variants and hemangioma are excluded. Well differentiated liposarcomas are predominantly fat with presence of thick (>2 mm) enhancing septations and nonfatty tissue. Dedifferentiated liposarcomas also have variable amount of nonfatty tissue. Myxoid liposarcomas have typical appearance of myxoid tissue (see later). Areas of round cell component within them have lower signal than the myxoid component on fluid sensitive sequences. Pleomorphic liposarcomas are high grade liposarcomas with imaging appearance similar to other sarcomas but the presence of identifiable fat still helps narrow the differential. However, some higher grade liposarcomas may not have visible fat (5).

The second group also has high signal on T1 weighted sequence but also has high or intermediate signal on T2 weighted sequence. This group represents tissue such as subacute blood as seen in hemorrhagic tumors, proteinaceous fluid as seen in lymphangioma/slow flow vascular malformation, or melanin as seen in melanoma and clear cell sarcoma (4).

The third group has relatively low signal on both T1 weighted sequence and T2 weighted sequence. This corresponds to fibrous tissue, hemosiderin or calcification (4). Plain radiographs are helpful to evaluate calcification. Highly cellular malignancy and lymphomas have relatively lower signal on fluid sensitive sequences. Additional MRI features seen in muscle lymphoma include involvement of more than one muscle compartment, direct involvement of the adjacent subcutaneous tissue and spread along the neurovascular bundle (90).

The last group, where most of the sarcomas fall, has intermediate signal on $\mathrm{T} 1$ weighted sequence and high signal on T2 weighted sequence (91). In this group cystic appearing lesions with very high $\mathrm{T} 2$ signal, but those that enhance with contrast, form a distinct group and mainly comprise of tumors with myxoid component such as myxoma, myxoid liposarcoma, and other myxoid sarcomas.

Some articles have further described clues that can further narrow the differential or suggest a possible etiology of sarcoma. For example, a deep lesion with fluid-like signal and enhancing fascial tail can suggest 
myxofibrosarcoma and undifferentiated sarcomas as possible diagnosis $(92,93)$.

\section{Staging}

Soft tissue sarcoma should ideally be managed by a multidisciplinary team with expertise in sarcoma (21). Staging of a lesion provides basis of management and prognosis. Staging is important for surgical planning as wide resection remains the mainstay of treatment of soft tissue sarcoma with or without adjuvant/neoadjuvant chemotherapy and/or radiation therapy. A biopsy proven soft tissue sarcoma, is usually staged further with CT scan of the chest (21). Due to their high probability for extrapulmonary metastasis, CT scan or MRI of the abdomen and pelvis may be obtained when an extremity myxoid liposarcoma is diagnosed, and CT (or MRI) of the brain may be obtained for extremity alveolar soft part sarcoma, clear cell sarcoma and angiosarcoma $(21,94-96)$.

Multiple staging systems are available and imaging plays an important role in its assessment. While the choice of which staging system to follow depends on the local institute, knowledge about these staging systems in necessary so that attention is paid to the various components of the system while reporting an imaging study. Of importance are the tumor size (both, the largest dimension, and three-dimensional measurement), location of the tumor in relation to the deep fascia, relationship to the other components that form a compartment such as bones and joints, invasion/encasement of the vessels and nerves, satellite nodule, lymph node metastasis, and distant metastasis. The extent of the peripheral reactive zone, and "fascial tail" if present, should also be clearly identified as it may contain tumor cells and has to be removed at surgery $(92,97)$. When the tumor contacts more than 180 degree of a vessels or nerve, encasement is suggested, with sensitivity for arterial, vein and nerve encasement of $84.6 \%, 84.6 \%$, and $77.8-72.2 \%$ respectively; and specificities of greater than $90 \%$ (98). Thrombus in a vessel near the soft tissue sarcoma can be due to direct invasion. Despite involvement of the vessels, a limb sparing surgery can still be performed but may need arterial and/or venous reconstruction (99). When the tumor abuts the vessels, it may lead to marginal resection and may necessitate post-operative radiation. Complete encasement of a major nerve, however, usually ends in amputation (Figure 17) (98). Invasion of the bone is seen in $5.5 \%$ of soft tissue sarcoma, seen as microscopic tumor invasion of the cortex or penetration into the medullary cavity, but is more common in synovial sarcoma (100). Whether the tumor is abutting the bone or invading the bone is important and MR images must be scrutinized to assess this. Signal alteration in the cortex on $\mathrm{T} 1$ weighted and $\mathrm{T} 2$ weighted sequences, and medullary cavity on T1 weighted sequence suggests invasion of cortex and medullary cavity respectively, if the tumor abuts the bone on T1 weighted sequence (101). The extent of marrow involvement however, can be better determined on $\mathrm{T} 1$ weighted sequence without fat saturation. If the tumor is abutting the bone, the periosteum is resected en bloc with tumor but with deeper invasion the bone must be resected (100). Joint involvement is uncommon occurring in about $2-3 \%(98)$.

\section{Monitoring of response to treatment}

The aim of monitoring the response to neoadjuvant chemotherapy is to identify nonresponders in whom the chemotherapy can be changed or stopped. Thus, the potential toxicity of the chemotherapy can be avoided. Imaging response to chemotherapy has traditionally been based on size as in Response Evaluation Criteria in Solid Tumors (RECIST) criteria. However, it may not truly predict the treatment response, and in this regard decreased attenuation on CT (as in Choi criteria) or decrease in tumor enhancement may be better (102). Functional changes at cellular level (metabolism, and tumor perfusion and permeability) occur earlier than anatomical change of decrease in size. In a patient on neoadjuvant chemotherapy, it is important to distinguish the increase in tumor size related to intralesional hemorrhage and necrosis from progressive disease (Figure 15). In addition, enhancement of granulation tissue and fibrosis that form as result of treatment response limits utility of traditional noncontrast and static post-contrast sequences for evaluation of treatment response. Multiple imaging techniques including DCE-MRI, DWI and ${ }^{18}$ F-FDG PET-CT have been used to monitor the early response to chemotherapy. Overall, with favorable tumor response, there is decrease in metabolism (decrease in SUV on ${ }^{18} \mathrm{~F}$-FDG PET) and perfusion (decrease in slope and delayed enhancement on DCE-MRI). In addition, there is increase in ADC values with decrease in tumor size (52).

\section{Postoperative follow up}

About $5-35 \%$ of soft tissue sarcoma show local recurrence 

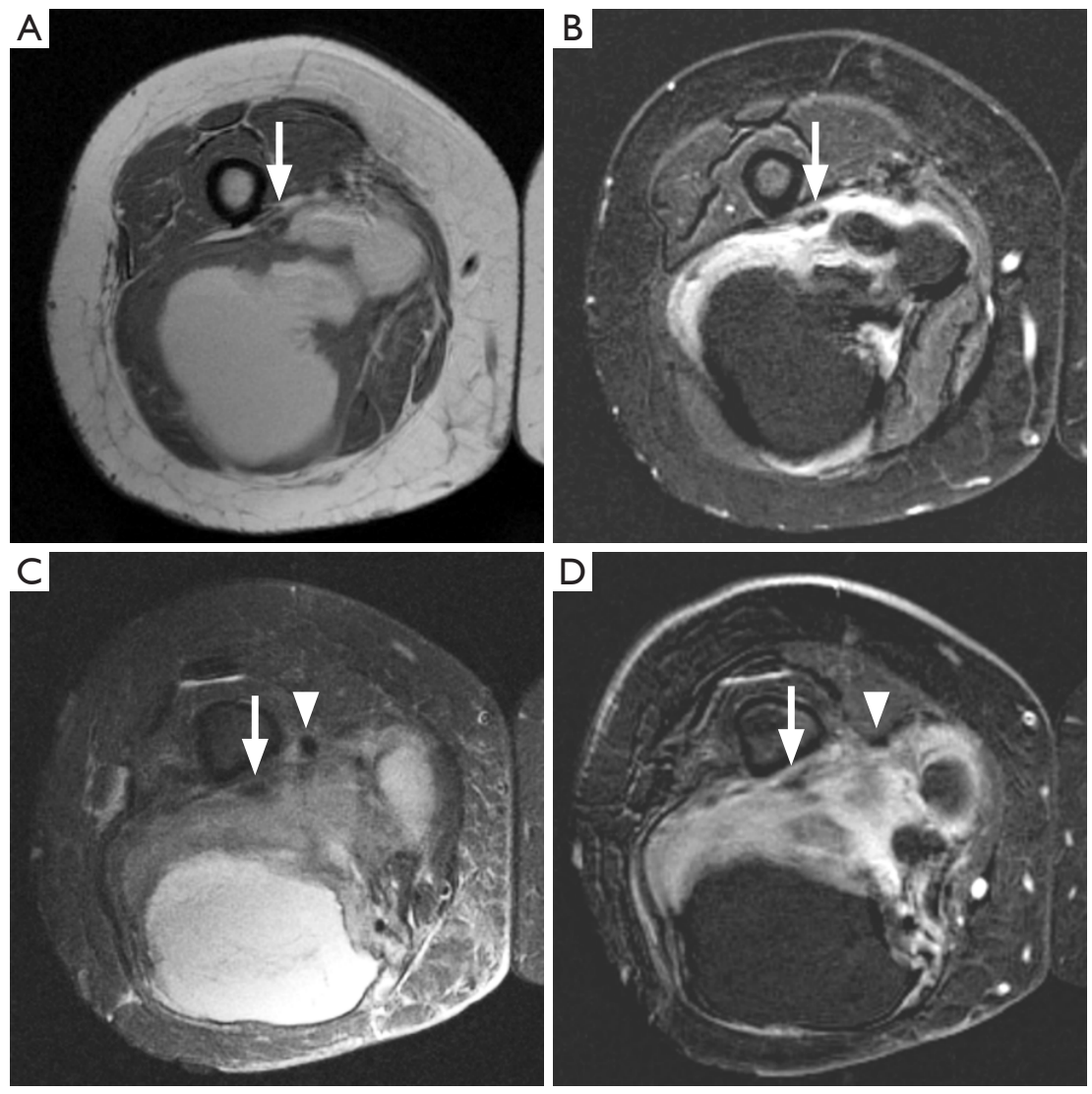

Figure 17 A 77-year-old woman with extraskeletal osteosarcoma. Axial T1 weighted (A) and post-contrast subtraction (B) images show the mass encircling the sciatic nerve (arrows). At a slightly different level, axial STIR (C) and post-contrast subtraction (D) images show edema and enhancement encircling the artery by greater than 180 degree (arrowheads). At surgery the nerve and artery were involved by the tumor at multiple sites and on frozen section of perivascular tissue, tumor cells were present.

with increased risk with high grade, deep location, and positive or close surgical margins. Most local recurrences appear within the first 2-3 years after initial surgery (21). There is no evidence based universally accepted guidelines for follow up of soft tissue sarcoma following resection. In general, a baseline study is performed 3-6 months postoperatively, followed by imaging every $3-6$ months up to 5 years, and then annually up to 10 years (19). Longer intervals are suggested for low grade tumors (21).

MRI is the imaging modality of choice for follow up of local resection site. Postoperative evaluation may be limited by the presence of artifact from metallic hardware or micrometallic debris in which case CT or US can be an alternative. The knowledge of previous clinical, surgical and therapeutic history including radiation therapy is essential for a more comprehensive assessment since soft tissue reconstruction such as a myocutaneous flap, vascular reconstruction, and prior radiation can create confusing appearance. Initial pretreatment imaging should be reviewed as the recurrence frequently has a similar appearance. In addition, previous postoperative surveillance images should also be reviewed and compared to, as immediate postoperative changes such as inflammation and granulation is expected to decrease over time. Changes related to the treatment are expected to diminish in a time related manner.

The recurrent tumor needs to be differentiated from areas of granulation, hemorrhage, seromas and radiation induced changes (Figure 18). Typical tumor recurrence is seen as discrete nodular region of increased fluid sensitive signal that enhances and has similar signal characteristics as original tumor. Exceptions do occur to this pattern, such as in myxofibrosarcoma where the recurrence can be infiltrative or occur in a superficial spreading manner with a tapering tail-like margin (103). On static post-contrast 

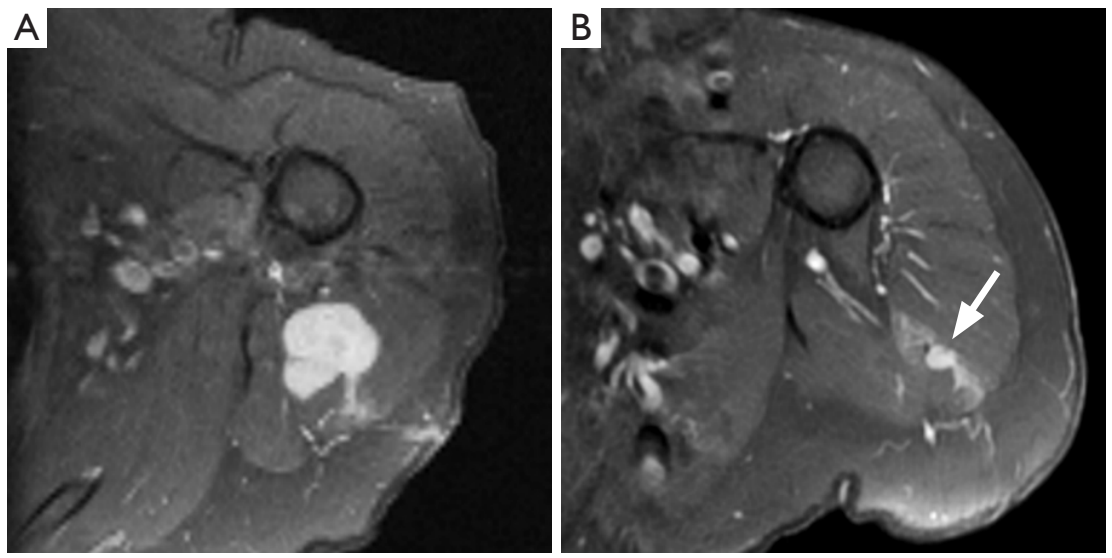

Figure 18 Axial post-contrast image (A) at initial presentation shows a mass proven to be an undifferentiated pleomorphic sarcoma. On post contrast T1FS image of surveillance MRI (B) an enhancing nodule (arrow) was seen suggesting tumor recurrence. However, at open biopsy this showed reactive changes only with no residual or recurrent sarcoma.

images granulation tissue and fibrosis can mimic tumor recurrence, but DCE-MRI and DWI significant increases the specificity of differentiating tumor recurrence from postsurgical scarring $(56,104,105) .{ }^{18} \mathrm{~F}$-FDG PET-CT can be used as problem solving tool and has comparable sensitivity and specificity as MRI for detecting local recurrence (106). It can evaluate for local and distant metastasis at the same time. However, biopsy may be needed to exclude a recurrence. The possibility of developing the rare radiation induced soft tissue sarcoma (most commonly undifferentiated pleomorphic sarcoma) after mean interval of 8-12 years should also be kept in mind (104).

\section{Conclusions}

We reviewed the various imaging modalities used in the diagnosis, initial staging, monitoring response to therapy, and subsequent postsurgical surveillance of soft tissue sarcoma. A multidisciplinary approach of management by a team with expertise and experience in soft tissue sarcomas cannot be overemphasized.

\section{Acknowledgements}

None.

\section{Footnote}

Conflicts of Interest: The authors have no conflicts of interest to declare.

\section{References}

1. Clark MA, Fisher C, Judson I, et al. Soft-tissue sarcomas in adults. N Engl J Med 2005;353:701-11.

2. Teniola O, Wang KY, Wang WL, et al. Imaging of liposarcomas for clinicians: Characteristic features and differential considerations. J Surg Oncol 2018;117:1195-203.

3. Simon MA, Finn HA. Diagnostic strategy for bone and soft-tissue tumors. J Bone Joint Surg Am 1993;75:622-31.

4. Wu JS, Hochman MG. Soft-tissue tumors and tumorlike lesions: a systematic imaging approach. Radiology 2009;253:297-316.

5. Gupta P, Potti TA, Wuertzer SD, et al. Spectrum of Fat-containing Soft-Tissue Masses at MR Imaging: The Common, the Uncommon, the Characteristic, and the Sometimes Confusing. Radiographics 2016;36:753-66.

6. Wang XL, Malghem J, Parizel PM, et al. Pictorial essay. Myositis ossificans circumscripta. JBR-BTR 2003;86:278-85.

7. Martinez S, Vogler JB 3rd, Harrelson JM, et al. Imaging of tumoral calcinosis: new observations. Radiology 1990;174:215-22.

8. Wilkerson BW, Crim JR, Hung M, et al. Characterization of synovial sarcoma calcification. AJR Am J Roentgenol 2012;199:W730-4.

9. Gartner L, Pearce CJ, Saifuddin A. The role of the plain radiograph in the characterisation of soft tissue tumours. Skeletal Radiol 2009;38:549-58.

10. Shapeero LG, Vanel D, Couanet D, et al. Extraskeletal mesenchymal chondrosarcoma. Radiology 1993;186:819-26. 
11. Kransdorf MJ, Meis JM. From the archives of the AFIP. Extraskeletal osseous and cartilaginous tumors of the extremities. Radiographics 1993;13:853-84.

12. Subhawong TK, Fishman EK, Swart JE, et al. Softtissue masses and masslike conditions: what does CT add to diagnosis and management? AJR Am J Roentgenol 2010;194:1559-67.

13. Panicek DM, Gatsonis C, Rosenthal DI, et al. CT and MR imaging in the local staging of primary malignant musculoskeletal neoplasms: Report of the Radiology Diagnostic Oncology Group. Radiology 1997;202:237-46.

14. Murphey MD, Carroll JF, Flemming DJ, et al. From the archives of the AFIP: benign musculoskeletal lipomatous lesions. Radiographics 2004;24:1433-66.

15. Knapp EL, Kransdorf MJ, Letson GD. Diagnostic imaging update: soft tissue sarcomas. Cancer Control 2005;12:22-6.

16. Expert Panel on Musculoskeletal I, Kransdorf MJ, Murphey MD, et al. ACR Appropriateness Criteria((R)) Soft-Tissue Masses. J Am Coll Radiol 2018;15:S189-97.

17. Li Y, Zheng Y, Lin J, et al. Evaluation of the relationship between extremity soft tissue sarcomas and adjacent major vessels using contrast-enhanced multidetector CT and three-dimensional volume-rendered CT angiography: a preliminary study. Acta Radiol 2013;54:966-72.

18. Aycock RD, Westafer LM, Boxen JL, et al. Acute Kidney Injury After Computed Tomography: A Meta-analysis. Ann Emerg Med 2018;71:44-53.e4.

19. Roberts CC, Kransdorf MJ, Beaman FD, et al. ACR Appropriateness Criteria Follow-Up of Malignant or Aggressive Musculoskeletal Tumors. J Am Coll Radiol 2016;13:389-400.

20. Reuther G, Mutschler W. Detection of local recurrent disease in musculoskeletal tumors: magnetic resonance imaging versus computed tomography. Skeletal Radiol 1990;19:85-90.

21. Group EESNW. Soft tissue and visceral sarcomas: ESMO Clinical Practice Guidelines for diagnosis, treatment and follow-up. Ann Oncol 2014;25 Suppl 3:iii102-12.

22. Sardenberg RA, Figueiredo LP, Haddad FJ, et al. Pulmonary metastasectomy from soft tissue sarcomas. Clinics (Sao Paulo) 2010;65:871-6.

23. Garcia-Figueiras R, Goh VJ, Padhani AR, et al. CT perfusion in oncologic imaging: a useful tool? AJR Am J Roentgenol 2013;200:8-19.

24. Widmann G, Riedl A, Schoepf D, et al. State-of-theart HR-US imaging findings of the most frequent musculoskeletal soft-tissue tumors. Skeletal Radiol
2009;38:637-49.

25. Amini B, Jessop AC, Ganeshan DM, et al. Contemporary imaging of soft tissue sarcomas. J Surg Oncol 2015;111:496-503.

26. Belli P, Costantini M, Mirk P, et al. Role of color Doppler sonography in the assessment of musculoskeletal soft tissue masses. J Ultrasound Med 2000;19:823-30.

27. Bermejo A, De Bustamante TD, Martinez A, et al. MR imaging in the evaluation of cystic-appearing soft-tissue masses of the extremities. Radiographics 2013;33:833-55.

28. Carra BJ, Bui-Mansfield LT, O'Brien SD, et al. Sonography of musculoskeletal soft-tissue masses: techniques, pearls, and pitfalls. AJR Am J Roentgenol 2014;202:1281-90.

29. Hung EH, Griffith JF, Ng AW, et al. Ultrasound of musculoskeletal soft-tissue tumors superficial to the investing fascia. AJR Am J Roentgenol 2014;202:W532-40.

30. Bui-Mansfield LT, Chen DC, O'Brien SD. Accuracy of ultrasound of musculoskeletal soft-tissue tumors. AJR Am J Roentgenol 2015;204:W218.

31. Gay F, Pierucci F, Zimmerman V, et al. Contrastenhanced ultrasonography of peripheral soft-tissue tumors: Feasibility study and preliminary results. Diagn Interv Imaging 2012;93:37-46.

32. Stramare R, Gazzola M, Coran A, et al. Contrast-enhanced ultrasound findings in soft-tissue lesions: preliminary results. J Ultrasound 2013;16:21-7.

33. Loizides A, Peer S, Plaikner M, et al. Perfusion pattern of musculoskeletal masses using contrast-enhanced ultrasound: a helpful tool for characterisation? Eur Radiol 2012;22:1803-11.

34. Gruber L, Loizides A, Luger AK, et al. Soft-Tissue Tumor Contrast Enhancement Patterns: Diagnostic Value and Comparison Between Ultrasound and MRI. AJR Am J Roentgenol 2017;208:393-401.

35. Gulati M, Hu JS, Desai B, et al. Contrast-Enhanced Sonography for Monitoring Neoadjuvant Chemotherapy in Soft Tissue Sarcomas. J Ultrasound Med 2015;34:1489-99.

36. Hahn S, Lee YH, Lee SH, et al. Value of the Strain Ratio on Ultrasonic Elastography for Differentiation of Benign and Malignant Soft Tissue Tumors. J Ultrasound Med 2017;36:121-7.

37. Li S, Liu L, Lv G. Diagnostic value of strain elastography for differentiating benign and malignant soft tissue masses. Oncol Lett 2017;14:2041-4.

38. Pass B, Jafari M, Rowbotham E, et al. Do quantitative and qualitative shear wave elastography have a role in 
evaluating musculoskeletal soft tissue masses? Eur Radiol 2017;27:723-31.

39. Delfaut EM, Beltran J, Johnson G, et al. Fat suppression in MR imaging: techniques and pitfalls. Radiographics 1999;19:373-82.

40. Lang P, Honda G, Roberts T, et al. Musculoskeletal neoplasm: perineoplastic edema versus tumor on dynamic postcontrast MR images with spatial mapping of instantaneous enhancement rates. Radiology 1995;197:831-9.

41. Panicek DM, Schwartz LH. Soft tissue edema around musculoskeletal sarcomas at magnetic resonance imaging. Sarcoma 1997;1:189-91.

42. Hardy PA, Kucharczyk W, Henkelman RM. Cause of signal loss in MR images of old hemorrhagic lesions. Radiology 1990;174:549-55.

43. Miwa S, Otsuka T. Practical use of imaging technique for management of bone and soft tissue tumors. J Orthop Sci 2017;22:391-400.

44. Verstraete KL, Lang P. Bone and soft tissue tumors: the role of contrast agents for MR imaging. Eur J Radiol 2000;34:229-46.

45. Verstraete KL, Van der Woude HJ, Hogendoorn PC, et al. Dynamic contrast-enhanced MR imaging of musculoskeletal tumors: basic principles and clinical applications. J Magn Reson Imaging 1996;6:311-21.

46. Shapeero LG, Vanel D, Verstraete KL, et al. Fast magnetic resonance imaging with contrast for soft tissue sarcoma viability. Clin Orthop Relat Res 2002:212-27.

47. van der Woude HJ, Verstraete KL, Hogendoorn PC, et al. Musculoskeletal tumors: does fast dynamic contrastenhanced subtraction MR imaging contribute to the characterization? Radiology 1998;208:821-8.

48. Tuncbilek N, Karakas HM, Okten OO. Dynamic contrast enhanced MRI in the differential diagnosis of soft tissue tumors. Eur J Radiol 2005;53:500-5.

49. van Rijswijk CS, Geirnaerdt MJ, Hogendoorn PC, et al. Soft-tissue tumors: value of static and dynamic gadopentetate dimeglumine-enhanced MR imaging in prediction of malignancy. Radiology 2004;233:493-502.

50. Verstraete KL, De Deene Y, Roels H, et al. Benign and malignant musculoskeletal lesions: dynamic contrastenhanced MR imaging--parametric "first-pass" images depict tissue vascularization and perfusion. Radiology 1994;192:835-43.

51. Costa FM, Ferreira EC, Vianna EM. Diffusion-weighted magnetic resonance imaging for the evaluation of musculoskeletal tumors. Magn Reson Imaging Clin N Am
2011;19:159-80.

52. Padhani AR, Koh DM. Diffusion MR imaging for monitoring of treatment response. Magn Reson Imaging Clin N Am 2011;19:181-209.

53. van Rijswijk CS, Kunz P, Hogendoorn PC, et al. Diffusion-weighted MRI in the characterization of softtissue tumors. J Magn Reson Imaging 2002;15:302-7.

54. Nagata S, Nishimura $H$, Uchida $M$, et al. Usefulness of diffusion-weighted MRI in differentiating benign from malignant musculoskeletal tumors. Nihon Igaku Hoshasen Gakkai Zasshi 2005;65:30-6.

55. Einarsdottir H, Karlsson M, Wejde J, et al. Diffusionweighted MRI of soft tissue tumours. Eur Radiol 2004;14:959-63.

56. Del Grande F, Subhawong T, Weber K, et al. Detection of soft-tissue sarcoma recurrence: added value of functional MR imaging techniques at 3.0 T. Radiology 2014;271:499-511.

57. Dudeck O, Zeile M, Pink D, et al. Diffusion-weighted magnetic resonance imaging allows monitoring of anticancer treatment effects in patients with soft-tissue sarcomas. J Magn Reson Imaging 2008;27:1109-13.

58. Subhawong TK, Wang X, Durand DJ, et al. Proton MR spectroscopy in metabolic assessment of musculoskeletal lesions. AJR Am J Roentgenol 2012;198:162-72.

59. Fayad LM, Barker PB, Bluemke DA. Molecular characterization of musculoskeletal tumors by proton MR spectroscopy. Semin Musculoskelet Radiol 2007;11:240-5.

60. Doganay S, Altinok T, Alkan A, et al. The role of MRS in the differentiation of benign and malignant soft tissue and bone tumors. Eur J Radiol 2011;79:e33-7.

61. Fayad LM, Wang X, Blakeley JO, et al. Characterization of peripheral nerve sheath tumors with $3 \mathrm{~T}$ proton MR spectroscopy. AJNR Am J Neuroradiol 2014;35:1035-41.

62. Drape JL. Advances in magnetic resonance imaging of musculoskeletal tumours. Orthop Traumatol Surg Res 2013;99:S115-23.

63. Bojadzieva J, Amini B, Day SF, et al. Whole body magnetic resonance imaging (WB-MRI) and brain MRI baseline surveillance in TP53 germline mutation carriers: experience from the Li-Fraumeni Syndrome Education and Early Detection (LEAD) clinic. Fam Cancer 2018;17:287-94.

64. Gorelik N, Reddy SMV, Turcotte RE, et al. Early detection of metastases using whole-body MRI for initial staging and routine follow-up of myxoid liposarcoma. Skeletal Radiol 2018;47:369-79.

65. Jager PL, Hoekstra HJ, Leeuw J, et al. Routine bone 
scintigraphy in primary staging of soft tissue sarcoma; Is it worthwhile? Cancer 2000;89:1726-31.

66. Ioannidis JP, Lau J. 18F-FDG PET for the diagnosis and grading of soft-tissue sarcoma: a meta-analysis. J Nucl Med 2003;44:717-24.

67. Folpe AL, Lyles RH, Sprouse JT, et al. (F-18) fluorodeoxyglucose positron emission tomography as a predictor of pathologic grade and other prognostic variables in bone and soft tissue sarcoma. Clin Cancer Res 2000;6:1279-87.

68. Eary JF, O'Sullivan F, Powitan Y, et al. Sarcoma tumor FDG uptake measured by PET and patient outcome: a retrospective analysis. Eur J Nucl Med Mol Imaging 2002;29:1149-54.

69. Eary JF, O'Sullivan F, O'Sullivan J, et al. Spatial heterogeneity in sarcoma $18 \mathrm{~F}-\mathrm{FDG}$ uptake as a predictor of patient outcome. J Nucl Med 2008;49:1973-9.

70. Rakheja R, Makis W, Tulbah R, et al. Necrosis on FDG PET/CT correlates with prognosis and mortality in sarcomas. AJR Am J Roentgenol 2013;201:170-7.

71. Wagner LM, Kremer N, Gelfand MJ, et al. Detection of lymph node metastases in pediatric and adolescent/ young adult sarcoma: Sentinel lymph node biopsy versus fludeoxyglucose positron emission tomography imaging-A prospective trial. Cancer 2017;123:155-60.

72. Fong Y, Coit DG, Woodruff JM, et al. Lymph node metastasis from soft tissue sarcoma in adults. Analysis of data from a prospective database of 1772 sarcoma patients. Ann Surg 1993;217:72-7.

73. Riad S, Griffin AM, Liberman B, et al. Lymph node metastasis in soft tissue sarcoma in an extremity. Clin Orthop Relat Res 2004:129-34.

74. Iagaru A, Chawla S, Menendez L, et al. 18F-FDG PET and PET/CT for detection of pulmonary metastases from musculoskeletal sarcomas. Nucl Med Commun 2006;27:795-802.

75. Roberge D, Vakilian S, Alabed YZ, et al. FDG PET/CT in Initial Staging of Adult Soft-Tissue Sarcoma. Sarcoma 2012;2012:960194.

76. Amini B, Madewell JE, Chuang HH, et al. Differentiation of Benign Fluid Collections from Soft-Tissue Sarcomas on FDG-PET/CT. J Cancer 2014;5:328-35.

77. Benz MR, Czernin J, Allen-Auerbach MS, et al. FDGPET/CT imaging predicts histopathologic treatment responses after the initial cycle of neoadjuvant chemotherapy in high-grade soft-tissue sarcomas. Clin Cancer Res 2009;15:2856-63.

78. Evilevitch V, Weber WA, Tap WD, et al. Reduction of glucose metabolic activity is more accurate than change in size at predicting histopathologic response to neoadjuvant therapy in high-grade soft-tissue sarcomas. Clin Cancer Res 2008;14:715-20.

79. Macpherson RE, Pratap S, Tyrrell H, et al. Retrospective audit of 957 consecutive 18F-FDG PET-CT scans compared to CT and MRI in 493 patients with different histological subtypes of bone and soft tissue sarcoma. Clin Sarcoma Res 2018;8:9.

80. Partovi S, Chalian M, Fergus N, et al. Magnetic resonance/positron emission tomography (MR/PET) oncologic applications: bone and soft tissue sarcoma. Semin Roentgenol 2014;49:345-52.

81. Zhang X, Chen YL, Lim R, et al. Synergistic role of simultaneous PET/MRI-MRS in soft tissue sarcoma metabolism imaging. Magn Reson Imaging 2016;34:276-9.

82. Cronin CG, Lohan DG, O'Riordan C, et al. Isolated limb infusion: technique description and clinical application. J Vasc Interv Radiol 2009;20:837-41.

83. Traina F, Errani C, Toscano A, et al. Current concepts in the biopsy of musculoskeletal tumors. J Bone Joint Surg Am 2015;97:e7.

84. Wu JS, McMahon CJ, Lozano-Calderon S, et al. JOURNAL CLUB: Utility of Repeat Core Needle Biopsy of Musculoskeletal Lesions With Initially Nondiagnostic Findings. AJR Am J Roentgenol 2017;208:609-16.

85. Kasraeian S, Allison DC, Ahlmann ER, et al. A comparison of fine-needle aspiration, core biopsy, and surgical biopsy in the diagnosis of extremity soft tissue masses. Clin Orthop Relat Res 2010;468:2992-3002.

86. Pohlig F, Kirchhoff C, Lenze U, et al. Percutaneous core needle biopsy versus open biopsy in diagnostics of bone and soft tissue sarcoma: a retrospective study. Eur J Med Res 2012;17:29.

87. Manaster BJ. Soft-tissue masses: optimal imaging protocol and reporting. AJR Am J Roentgenol 2013;201:505-14.

88. De Schepper AM, Ramon FA, Degryse HR. Statistical analysis of MRI parameters predicting malignancy in 141 soft tissue masses. Rofo 1992;156:587-91.

89. Kransdorf MJ. Malignant soft-tissue tumors in a large referral population: distribution of diagnoses by age, sex, and location. AJR Am J Roentgenol 1995;164:129-34.

90. Suresh S, Saifuddin A, O'Donnell P. Lymphoma presenting as a musculoskeletal soft tissue mass: MRI findings in 24 cases. Eur Radiol 2008;18:2628-34.

91. De La Hoz Polo M, Dick E, Bhumbra R, et al. Surgical considerations when reporting MRI studies of soft tissue sarcoma of the limbs. Skeletal Radiol 2017;46:1667-78. 
92. Yoo HJ, Hong SH, Kang Y, et al. MR imaging of myxofibrosarcoma and undifferentiated sarcoma with emphasis on tail sign; diagnostic and prognostic value. Eur Radiol 2014;24:1749-57.

93. Lefkowitz RA, Landa J, Hwang S, et al. Myxofibrosarcoma: prevalence and diagnostic value of the "tail sign" on magnetic resonance imaging. Skeletal Radiol 2013;42:809-18.

94. Sood S, Baheti AD, Shinagare AB, et al. Imaging features of primary and metastatic alveolar soft part sarcoma: single institute experience in 25 patients. Br J Radiol 2014;87:20130719.

95. Shweikeh F, Bukavina L, Saeed K, et al. Brain metastasis in bone and soft tissue cancers: a review of incidence, interventions, and outcomes. Sarcoma 2014;2014:475175.

96. Dim DC, Cooley LD, Miranda RN. Clear cell sarcoma of tendons and aponeuroses: a review. Arch Pathol Lab Med 2007;131:152-6.

97. Kransdorf MJ, Murphey MD. The use of gadolinium in the MR evaluation of soft tissue tumors. Semin Ultrasound CT MR 1997;18:251-68.

98. Holzapfel K, Regler J, Baum T, et al. Local Staging of Soft-Tissue Sarcoma: Emphasis on Assessment of Neurovascular Encasement-Value of MR Imaging in 174 Confirmed Cases. Radiology 2015;275:501-9.

99. Schwarzbach MH, Hormann Y, Hinz U, et al. Results

Cite this article as: Patel DB, Matcuk GR Jr. Imaging of soft tissue sarcomas. Chin Clin Oncol 2018;7(4):35. doi: 10.21037/ cco.2018.07.06 of limb-sparing surgery with vascular replacement for soft tissue sarcoma in the lower extremity. J Vasc Surg 2005;42:88-97.

100. Ferguson PC, Griffin AM, O'Sullivan B, et al. Bone invasion in extremity soft-tissue sarcoma: impact on disease outcomes. Cancer 2006;106:2692-700.

101. Elias DA, White LM, Simpson DJ, et al. Osseous invasion by soft-tissue sarcoma: assessment with MR imaging. Radiology 2003;229:145-52.

102. Stacchiotti S, Verderio P, Messina A, et al. Tumor response assessment by modified Choi criteria in localized high-risk soft tissue sarcoma treated with chemotherapy. Cancer 2012;118:5857-66.

103. Waters B, Panicek DM, Lefkowitz RA, et al. Low-grade myxofibrosarcoma: CT and MRI patterns in recurrent disease. AJR Am J Roentgenol 2007;188:W193-8.

104. Garner HW, Kransdorf MJ, Bancroft LW, et al. Benign and malignant soft-tissue tumors: posttreatment MR imaging. Radiographics 2009;29:119-34.

105. Garner HW, Kransdorf MJ. Musculoskeletal Sarcoma: Update on Imaging of the Post-treatment Patient. Can Assoc Radiol J 2016;67:12-20.

106. Park SY, Chung HW, Chae SY, et al. Comparison of MRI and PET-CT in detecting the loco-regional recurrence of soft tissue sarcomas during surveillance. Skeletal Radiol 2016;45:1375-84. 